\title{
Latino gentrificación y polarización: transformaciones socioespaciales en barrios pericentrales y periféricos de Santiago, Chile ${ }^{1}$
}

\author{
Jorge Inzulza² y Ximena Galleguillos ${ }^{3}$
}

\begin{abstract}
RESUMEN
Gentrificación y segregación, son fenómenos urbanos de diferenciación social y espacial complejos y controversiales a escala global. Santiago de Chile, al igual que otras megaciudades latinoamericanas, experimentó una rápida expansión urbana con diferenciación social. Específicamente, en las últimas décadas, la gestión inmobiliaria en esta ciudad está protagonizando transformaciones urbanas en el habitar, tanto el pericentro como la periferia, generando una cercanía geográfica aparente entre habitantes pobres y mejor situados. Sin embargo, estas mutaciones socioespaciales parecen perder de vista la forma urbana y sus estructuras de sentido para la vida ciudadana. ¿Qué efectos tipológicos y topológicos, se pueden reconocer en el pericentro y en la periferia producto de estas transformaciones? A partir de un análisis contextual, teórico y empírico en dos barrios en Santiago de Chile -El Llano Subercaseaux pericentral histórico, y Parque Violeta Cousiño periférico "emergente"- se examinan estos procesos de transformación socioespacial. Los hallazgos de este análisis -sistematizados por medio de una matriz topológica y tipológica- permiten establecer distinciones que muestran tendencias a latino gentrificación pericentral y polarización periférica.
\end{abstract}

Palabras clave: Transformación socioespacial, barrio, tipología y topología, latino gentrificación, polarización.

\begin{abstract}
Gentrification and segregation are complex and controversial urban phenomena of social and spatial differentiation at global scale. Similar to other Latin American megacities, Santiago, Chile has undergone a rapid urban expansion with social disparities. Specifically, in recent decades, real estate development has modified the urban lifestyle in peri-central and peripheral areas, producing a geographical proximity between low and high-income residents that needs to be debated. However, these socio-spatial transformations appear to have lost sight of the original urban fabric, as well as people's values and collective memories. Which typological and topological effects can be recognized in Santiago's peri-central and peripheral zones as a result of these changes? Based on a contextual, theoretical and empirical analysis, we discuss the socio-spatial transformations of two neighborhoods in Santiago, Chile: El Llano Subercaseaux (a historical peri-central neighborhood) and Parque Violeta Cousiño (an emergent neighborhood on the city's periphery). The research findings, which are systematized by a topological and typological matrix, provide conclusions about trends in peri-central Latino gentrification and peripheral polarization.
\end{abstract}

Key words: Socio-spatial transformation, neighborhood, typology and topology, Latino gentrification, polarization.

1 Este artículo ha sido elaborado en el marco del proyecto CONICYT/FONDAP/15110020.

2 Departamento de Urbanismo, Universidad de Chile (Chile). E-mail: jinzulza@uchilefau.cl

\footnotetext{
3 Universidad de Kiel (Alemania). E-mail: galleguillos@geographie.uni-kiel.de
} 
Tanto en el contexto latinoamericano como general, las transformaciones socioespaciales de la estructura urbana de las grandes ciudades son un fenómeno territorial paradigmático en el desarrollo urbano. Si la sociedad moderna e industrial se caracterizaba por una estructura social relativamente estable, simple, clara o con conflictos de clase tipificados, la contemporánea se presenta mucho más compleja y fragmentada. El fenómeno de diferenciación socioespacial causal de esta fragmentación incluye categorías de discriminación construidas social y culturalmente, las que se intersectan generando múltiples formas de discriminación (Crenshaw, 2005; Graham, 1990; Dorlin, 2007; Viveros, 2009). Los efectos de estos procesos son la desarticulación espacial a que la mayoría de los habitantes de barrios centrales y periféricos en las grandes ciudades latinoamericanas están expuestos, el bloqueo de la relación entre vecinos, discriminacíon entre ricos y pobres en la dotación de infraestructura urbana e inversión privada, y donde la dureza de las condiciones de vida en la ciudad, que en los últimos años se han agravado por un aumento de la violencia y criminalidad, alimentan el círculo vicioso para una creciente diferenciación socioespacial.

En este contexto, las tendencias actuales de la diferenciación social en la ciudad latinoamericana como fenómenos de carácter global y local, son frecuentemente tipificadas como gentrificación y segregación. No obstante la dinámica de cambios de estos procesos requiere de un examen permanente de las particularidades locales que presentan, y por el impacto que se les atribuye en la vida urbana barrial. Como la mayoría de las megaciudades latinoamericanas, Santiago de Chile no ha estado exenta de un proceso de expansión acompañado de diferenciación socioespacial y desde la perspectiva de la evolución de este fenómeno, y constituye un caso especial en América del Sur: desde la época del gobierno militar de Pinochet en los años 1970 y 1980 y durante décadas el desarrollo urbano sigue estando marcado por un enfoque de política urbana neoliberal evidenciado en sus estrategias y sus principales actores, y cuyos efectos se caracterizaron en su comienzo por procesos de segregación socioespacial (Bähr y RiesCo, 1981).
La dinámica de las estrategias neoliberales de uso del suelo, ha ido transformando zonas urbanas en "espejos" globales de la modernidad, en forma de sectores financieros estilo Sanhattan y en megaproyectos postsuburbanos. La gestión inmobiliaria a través de la inversión en proyectos habitacionales ha ido paulatinamente gatillando nuevos procesos derivados del mismo fenómeno de diferenciación social (Galleguillos, 2012), en un escenario de cercanía geográfica entre habitantes pobres y mejor situados. La estructura urbana de los barrios pobres se transforma en fragmentos sociespacialmente precarios en una excepcionalmente reducida escala geográfica con signos de polarización (Wehrhahn y Lukas, 2013). Con la cercanía geográfica entre grupos socioeconómicos distintos (Galleguillos, 2007), la segregación socioespacial desdibuja su dimensión geográfica de considerables distancias entre grupos socioeconómicos distintos, grandes conglomerados habitacionales y homogeneidad social en pobreza (Galleguillos, 2007), generando nuevas formas de diferenciación. Así también, la transformación socioespacial en las áreas centrales de la ciudad muestra signos de diferenciación social en forma de latino gentrificación (Inzulza, 2012a) y polarización (Galleguillos, 2012; Wehrhahn y Lukas, 2013).

¿Qué efectos de forma y fondo se pueden reconocer en el pericentro histórico y en la periferia producto de las transformaciones socioespaciales barriales? El objetivo de la presente investigación es revisar y reflexionar acerca de estos procesos de cambio físico y social para lograr una mayor comprensión de sus particularidades, vinculaciones e implicancias en el contexto latinoamericano y en el ejemplo de Santiago de Chile. La hipótesis plantea que las transformaciones socioespaciales barriales urbanas producto del desarrollo inmobiliario y la falta de regulación en Santiago de Chile, revelan una pérdida de vista de la forma urbana y sus estructuras de sentido para la vida ciudadana, generando los fenómenos de latino gentrificación y polarización, con implicancias negativas para el logro de sustentabilidad social urbana.

El primer capítulo explora cuestiones teóricas de fondo y de forma de fenómenos asociados a la diferenciación socioespacial, a 
esto se suma en el análisis la política urbana, así como el "consumo" de la vivienda en el contexto neoliberal chileno y latinoamericano. El segundo capítulo realiza un análisis contextual téorico y empírico de los fenómenos de gentrificación y segregación, para dos barrios: El Llano Subercaseaux por caracterizarse como barrio pericentral histórico localizado en la comuna de San Joaquín, y Parque Violeta Cousiño por caracterizarse como barrio periférico emergente de la comuna de Peñalolén. Los resultados son sistematizados en una matriz tipológica y topológica. Finalmente, las conclusiones ponen de relevancia la relación entre las estructuras barriales resultantes, y las implicancias de los fenómenos de diferenciación socioespacial para propósitos de sustentabilidad urbana. A partir de estas reflexiones, se promueve el enfoque del urbanismo ciudadano caracterizado por una política urbana, centrada en la valoración de la realidad plural y diversa de los barrios y comunidades, con el desafío permanente de adaptar y flexibilizar las propuestas de intervención territorial, en un marco de regeneración urbana barrial integral para el diseño de políticas públicas en materia de desarrollo urbano.

\section{La diferenciación socioespacial y efectos de la política urbana: una cuestión de fondo}

El Estado y el mercado son hoy en día los agentes que plantean los parámetros, de acuerdo a los cuales, se efectúa la distribución de personas, recursos, y actividades. Mediante sus diversos programas y estrategias, desde el planeamiento urbano, la regulación económica, la política fiscal, y la inversión infraestructural hasta la provisión diferenciada espacialmente de bienes y servicios públicos como la vivienda, la educación, la salud, el bienestar, y la policía. Mediante su estructura y su política, sus acciones e inacciones programadas, determina el alcance, la difusión, e intensidad de la marginalidad en la ciudad. Esto significa que, en la medida en que colaboran en dar forma al paisaje urbanístico, participan en la producción del espacio de la relegación socioespacial (Wacquant, 2011). Así también, los medios de comunicación contribuyen en gran medida al reforzamiento del confinamiento territo- rial de nuestras ciudades al aplicar una operación de reducción consistente en clausurar la identidad de las personas en torno a su pertenencia territorial (Bauman, 2006, 2011).

Por otra parte, la comunidad, aunque principal afectado por los efectos de las políticas urbanas, tiende a acentuar estos procesos. Según Martínez (2006), la comunidad está dada por individuos que comparten un estar en común. Una comunidad es un agregado que se construye sobre el principio de la alteridad. Ontológicamente, la comunidad es lo primero y el proceso de individualización, de personalización solo puede producirse al interior de una comunidad. El ámbito de acción es la vida cotidiana, en contextos territoriales, con reglas de producción y reproducción que le son propias. Las prácticas comunitarias transforman el espacio social, lo 'significan' físicamente, y solidifican las construcciones. El sentido de comunidad para los vecinos se puede construir y dinamizar, por ejemplo, en torno a la inseguridad, generando cohesión social a partir de un sentido comunitario de inseguridad que contribuye a reforzar las estructuras de fragmentación propiciadas por las políticas urbanas (Martínez, 2006).

\section{Zonificación, confinamiento territorial, gentrificación}

La zonificación surgió en Alemania en la segunda mitad del siglo XIX (Ladd, 1990). Justificaciones ambientales políticas y sociales y de higienización encubrieron los intereses en favor de la segregación social urbana, formalizando la tendencia de grupos urbanos de mayores ingresos de muchas ciudades europeas a segregarse en zonas monofuncionales y socialmente homogéneas y excluyentes. La zonificación, ha contribuido a agudizar externalidades como la congestión, la contaminación, la inseguridad ciudadana y la homogeneidad socioeconómica, que se traduce en extensiones urbanas de pobreza aglomerada y "dura". Se ubica entre los factores que causan una agudización en la fricción espacial en la ciudad, donde cientos de miles de habitantes diariamente deben recorrer enormes distancias con las consiguientes consecuencias socioambientales. Entre los efectos de estas configuraciones territoriales está el confina- 
miento territorial externo que en el caso de comunidades pobres es construido desde fuera y puede ser vivenciado muy negativamente por sus habitantes. Adopta la forma de autoconfinamiento cuando la comunidad (sectores medios y altos de la sociedad) se dinamiza frente al riesgo, peligro, desconfianza de los otros (de las otras comunidades peligrosas) y se convierte en el principal vector de sentido (cohesión social). Para su existencia cotidiana transforman espacios públicos en espacios cerrados. Operando de esta manera el confinamiento territorial configura para nuestras ciudades un clima de separación y desconfianza, compuesto de distancias cercadas y protegidas donde se criminaliza la diferencia (Bauman, 2011, 2006; Martínez, 2006). La seclusión socioespacial es el concepto que utiliza Wacquant (2011) y que complementa la definición de Bauman $(2011,2006)$ del proceso por el que se se cercan y se aíslan determinadas categorías y actividades sociales en un espacio físico y social.

Las formas tienen que ver con el nivel en la jerarquía social, que incluye la clase, etnicidad, o el prestigio de los lugares, las que por lo general están estrechamente relacionadas y la segunda dimensión es el carácter voluntario de libre elección de limitar la presencia del otro a una zona particular, o el verse en la obligación por fuerzas exteriores a limitar su residencia a una ubicación dada. En el primer caso este proceso es orientado y consolidado por la afinidad desde adentro, y en el segundo por la hostilidad desde afuera. La autoseclusión que es alimentada por una orientación grupal interna está representada por enclaves de elite o distritos tradicionales de clases altas en la ciudad y por los "barrios cerrados" que se han expandido en lo alto de la jerarquía social y espacial durante las dos últimas décadas, concretado con límites físicos, vallas con verjas y guardias para vigilancia y protección (Wacquant, 2011). De este análisis, Wacquant $(2010,2011)$ identifica cuatro elementos estructurales en la diferenciación social que sustentan su teoría del gueto urbano como proyecto y que refutan la presencia del gueto en la diferenciación socioespacial actual. El primero es el estigma, el segundo elemento es la restricción resultado de una imposición exterior, el tercer constituyente es la asignación espacial, de modo que se tiene una implicancia en un do- ble sentido de categoría y territorio que lleva a la homogeneidad y exclusividad étnicas. El cuarto elemento es el paralelismo institucional. Como a la población se la presiona para residir en su distrito asignado, desarrolla una red de instituciones que sustituyen las instituciones de la sociedad amplia, de la cual es rechazada.

El gueto es un instrumento de subordinación y un conducto para protección, unificación, y cohesión al mismo tiempo, a diferencia de ser factor de desesperanza aprendida, principal característica del gueto identificada por Seligman (1979). Siguiendo las argumentaciones de Wacquant (2011) esta característica actualmente es un signo de las nuevas relegaciones urbanas. Este autor, en el ejemplo de USA, demuestra la inaplicabilidad del término a los procesos actuales al identificar tres características entre gueto y los procesos de diferenciación socioespacial en el ejemplo del contexto de USA en la década de 1910, el gueto comunal que floreció hacia 1950 y se hundió a fines de la década de 1960 (Wacquant, 2010, 2011). La primera, es que carecen de una función económica, por cuanto la fuerza de trabajo que contiene ha pasado a ser excedente. La segunda, están doblemente segregados por raza y por clase. La tercera característica, es que han sido despojados de las instituciones que constituían la estructura de la vida cotidiana. En resumen, las transformaciones socioespaciales urbanas barriales en el ejemplo de USA se muestran como mecanismos socioespaciales adaptados para la exclusión abierta, que divide a la comunidad negra a lo largo de líneas de clase y no ofrece ninguna de las protecciones colectivas y beneficios colaterales de la guetización. Lo que ocurre en Europa, son áreas socioespacialmente mezcladas y no guetos de inmigrantes en lo que se refiere a la ocupación como a la etnicidad. Históricamente, su anclaje ha sido la integración al mundo del trabajo asalariado, los servicios municipales, los vecindarios de obreros y la vida en familia y comunidad. Pero esta vinculación se fue deshaciendo bajo la presión de la desindustrialización y la desocupación masiva, la universalización de la enseñanza como una forma de acceder a posiciones sociales más valoradas, y los cambios en la política estatal. Durante las tres últimas décadas, los gobiernos de Europa Occidental han 
comenzado a otorgar subsidios para hogares individuales para ayudarlos a ingresar al mercado de la casa individual lo que ha permitido a familias de clase media baja abandonar las grandes urbanizaciones del sector público y emigrar a casas individuales en terrenos privados. Esta política ha dejado atrás a las familias de la clase obrera, justamente cuando estas estaban siendo protagonistas de un dramático crecimiento del desempleo y la proliferación de los empleos precarios. El resultado ha sido el deterioro físico, la pauperización económica, y la denigración pública de la periferia urbana.

En este sentido, las tendencias en las transformaciones socioespaciales de los distritos en obsolescencia de las metrópolis europeas muestran que los distritos indigentes del cinturón rojo parisiense y las banlieues de Francia se han vuelto menos homogéneos durante las últimas dos décadas. Un segundo indicador es que los territorios obreros de Europa Occidental, desde la región central de Inglaterra al Ruhr alemán y a los quartieri degradati de las ciudades del norte de Italia, muestran decadencia y muerte de las organizaciones locales, en particular las que auxiliaban a la clase obrera industrial en las esferas del trabajo y del vecindario. En tercer lugar, los territorios obreros de Europa Occidental y los residentes de las banlieues siguen estando divididos por clase, nacionalidad, etnicidad, edad, y generación. La cuarta tendencia muestra que las familias de los inmigrantes poscoloniales que ascienden en la estructura de clase -mediante el sistema escolar, pequeño empresariado, empleo asalariado (a menudo en el sector público), o uniones matrimoniales- inmediatamente se mudan de los vecindarios pobres, es decir, la movilidad social ascendente conduce a una dispersión espacial e integración social (compare Wacquant, 2011, 2010). En resumen, los municipios de las clases bajas de las metrópolis europeas se están volviendo étnicamente más heterogéneos y organizacionalmente menos estructurados; sus fronteras son porosas y sin una identidad cultural compartida.

En este escenario, la gentrificación aparece en un contexto de creciente tendencia a recuperar la perspectiva urbana de la diversidad socioespacial en oposición al confinamiento territorial y segregación social urbana producto de las catastróficas consecuencias de la política del Zoning. Los nuevos proyectos inmobiliarios y ofertas de viviendas $y$ espacios concebidos prometen la conección de las diversas funciones en la ciudad (trabajar, habitar una vivienda, abastecerse, utilizar el tiempo libre) en una relativa cercanía a la vecindad o conjunto residencial, lo que a su vez reduce la fricción causada por una movilidad individual extrema y la necesidad de recurrir a una movilidad motorizada, favoreciendo el desarrollo de estrategias de low-impact. La gentrificación es justamente el resultado del cruce de estrategias de mezcla social y funcional, con los intereses del sector inmobiliario y actores privados de estratos socioeconómicos medios y altos.

\section{Latino gentrificación}

Aunque el proceso de gentrificación no ha cambiado en esencia desde los efectos conocidos de desplazamiento de población obrera o de menor ingreso, por población de clase media y alta (burguesía), así como el incremento del precio de suelo urbano analizado en las experiencias iniciales europeas (Glass, 1964); compilaciones de Appleyard (1979) y Carpenter y Lees (1995); y trabajos norteamericanos descritos por Ley (1987), Zukin (1988), Smith (1996) o Ulusoy (1998); se pueden identificar particularidades físicas y socioespaciales de este proceso de diferenciación en la actualidad. En este sentido, este proceso es asociado con otros indicadores tales como tensiones provocadas por relaciones de género (Bondi, 1999; Smith, 2005), fragmentación del espacio urbano (Carpenter \& Lees, 1995; Caldeira 2000; Lungo y Baires 2001; Hidalgo et al., 2003), formas nuevas de consumo de cultura, una nueva clase media, supergentrificadores viviendo en Londres (Butler \& Hamnett 1994; Hamnett 2003, 1991; Lees 1996, 1994; Lyons 1996); y su relación con el proceso de globalización (Sassen 1991; Ciccolella 1999; Thompson 2001; Wyly \& Hammel 2005; Rubino 2005).

Un análisis de las tendencias de este fenómeno muestra una clara "mutación" como es definido por Lees et al. (2008) y Davidson y Lees (2010); desde un proceso más esporádico en su origen (1960s), hacia un fenómeno global que en la actualidad que puede ser visto a lo largo del todo el mundo. En este 
sentido, se puede decir que la globalización tiene un rol crucial en la transformación de la mayoría de las áreas urbanas consolidadas desde los 80, cambiando tanto la estructura física como social de muchos barrios históricos. De esta forma, los ciclos de la gentrificación resumidos en el Cuadro $N^{\circ} 1$, asocian la globalización a este fenómeno, explicando con ello, la mayor cantidad de cambios físicos y sociales observados en el centro de las ciudades. Una estrecha relación entre el Estado y el sector privado parece ser la principal estrategia usada para renovar los centros urbanos históricos (Lees et al., 2008; Lees \& Ley, 2008).

Asimismo, inversionistas y empresarios han logrado acuerdos específicos con la clase media social, transformando el centro histórico en un commodity ligado con la gestión de suelo urbano y la especulación inmobiliaria. La ciudad histórica central o inner city, como el primer y principal escenario urbano de la gentrificación, ha atraído la atención de in- versiones y acciones de renovación urbana, pero si observamos manifestaciones de gentrificación clásicas como la transformación de casas victorianas inglesas o ex fábricas convertidas en Lofts del SoHo neoyorquino; los edificios en altura indican un cambio que va más que desplazamiento de clases, al reemplazo y densificación del tejido social existente, así también, la presencia de nuevos artistas gráficos más que la llegada de clases burguesas como los gentrificadores originales, indican una gentrificación contemporánea de tercer e incluso de cuarto ciclo, que marca una clara diferencia con el primer y segundo ciclo de este fenómeno.

El fenómeno de latino gentrificacion (Inzulza, 2012a, 2012c), se puede observar en cuatro particularidades: 1) Presencia de pobreza urbana y exclusión social, lo cual divide la ciudad central en áreas dispares (Portes, 1989; The World Bank, 2000; Rodríguez y Winchester, 2004). 2) Como principal expresión física de esta exclusión social, se

Cuadro $\mathrm{N}^{\circ} 1$

Los ciclos de la gentrificación desde 1960 hasta el presente

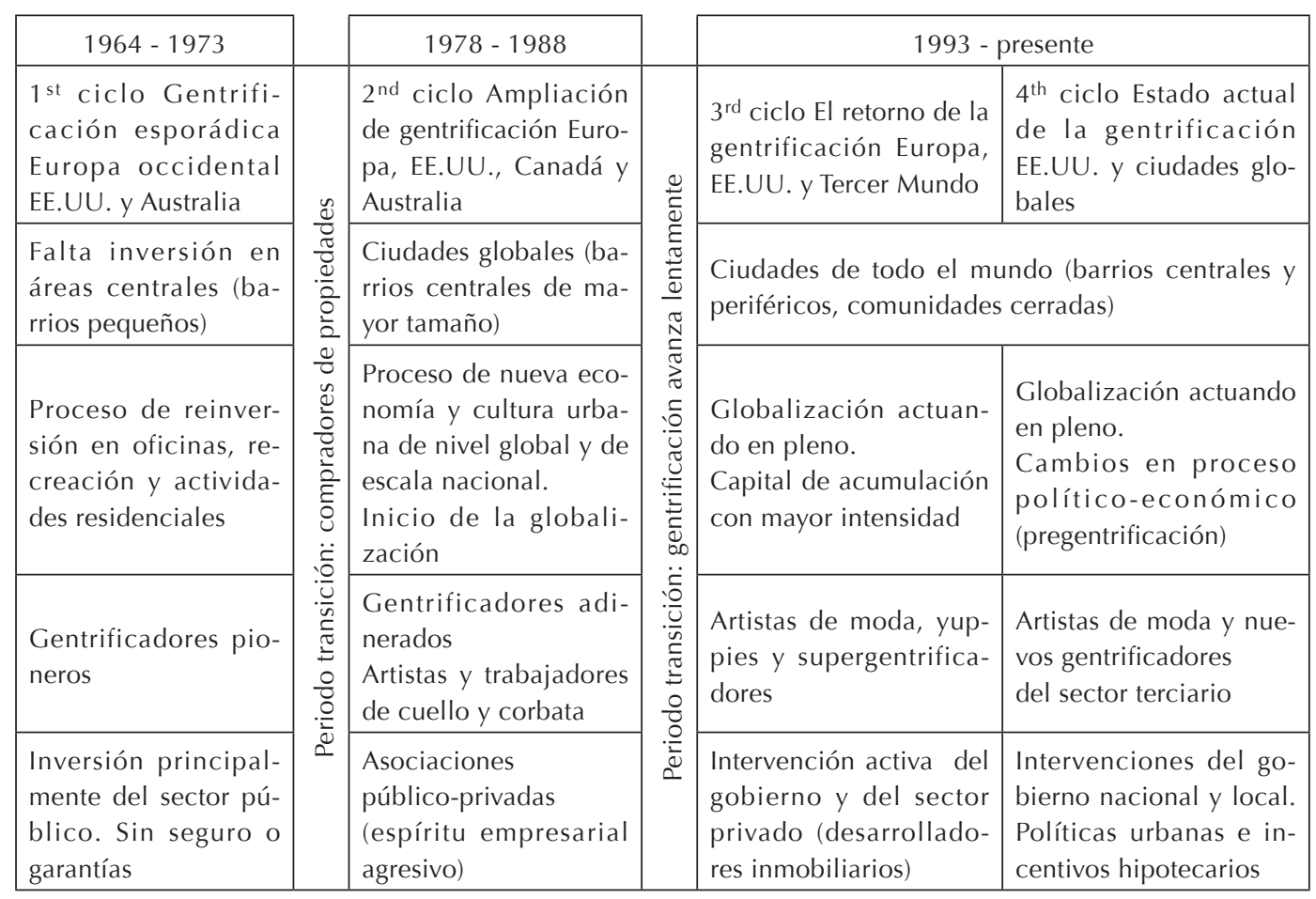

Fuente: basado en Inzulza (2012b); Lees et al. (2008); Cameron y Coaffee (2005); Hackworth y Smith (2001). 
advierten tendencias a vivir en comunidades cerradas principalmente proyectos inmobiliarios de vivienda en altura, y en la mayoría de los casos, promovidos por los gobiernos nacionales y locales a través de subsidios económicos de adquisición (Rojas, 2004). 3) Los consumidores de estos tipos de viviendas en altura, caracterizados por gente ligada a trabajos del sector terciario y de ingresos medios, están eligiendo los barrios centrales para establecer un tipo de vida urbana "de moda" y cerca de sus trabajos (Bourdieu, 1997; Arizaga, 2003); y 4). Esta tendencia de uso está fuertemente ligada con un incremento en el consumo de commodities, como pueden ser vistos los nuevos departamentos, diseñados para jóvenes profesionales, viviendo solos o en pareja, con o sin hijos, e interesados en tener una vivienda con una cierta apariencia 'global' y estándares de seguridad entregados por conjuntos enrejados y cámaras de seguridad (Borsdorf et al., 2007; Hidalgo et al., 2003). Estas distinciones constituyen un primer argumento para identificar un proceso de latino gentrificación (Inzulza, 2012b) en los barrios históricos del Gran Santiago.

\section{El barrio histórico en términos genéricos}

Corresponde a una tipología de barrio definido por su localización central y pericentral en el núcleo fundacional de la ciudad y, por lo tanto, ligado con sus orígenes y cuya consolidación normalmente fue originada por su vocación residencial. Sus residentes constituyen tradicionalmente comunidades con considerable interacción entre vecinos y permanencia en el barrio desde sus orígenes (Almandoz, 2006; Fitch, 1990; Inzulza, 2012b; Ormindo, 2002; Pavez, 2008; Rojas, 2004). El barrio histórico posee una morfología caracterizada por el área urbana en sí misma con una zona bien delimitada por su patrimonio arquitectónico (vivienda y edificios públicos) además de estar dotado de un espacio público con un estilo particular propio de históricos planes y políticas urbanas (mobiliario urbano, parques, jardines, luminarias, etc.). A esta dimensión física se suma un alto sentido de pertenencia e identidad global y local de sus habitantes (Robertson, 2003).

El espacio construido está íntimamente ligado con el tejido social, posee alto sentido de imageability, propuesto por Lynch (1971) para significar que sus componentes físicos se lugarizan o adquieren sentido y pueden ser identificados y apropiados por sus residentes y así utilizados apropiadamente. El segundo componente está formado por el tejido social y la estructura socioeconómica, donde distintos tipos de actores urbanos juegan un rol activo. Aunque los barrios históricos trascienden en pertenencia e identidad sus límites físicos y sus residentes, estos mismos desarrollan altos grados de cohesión social. El barrio central histórico representa un ambiente adecuado para los residentes dado que en sí mismo constituye un collage de tiempo (Lynch, 1971), permitiendo conectar activamente el presente tanto con el futuro como con el pasado (Hayden, 1995; Hebbert, 2005). Más aún, el barrio central histórico es parte de un conjunto, formado por un sistema de barrios que conviven por medio de relaciones perceptuales, tipológicas, ecosistémicas y funcionales. Estas características permiten acercarnos al imaginario de lo que podría ser un barrio sustentable, entendiendo por sustentabilidad o desarrollo sustentable, el proceso que involucra el ensayo de una área urbana y su interacción con el medio físico, social y económico, y estos aspectos, asociados a una dimensión espacio-temporal (Naredo, 1996; Van Kamp et al., 2003).

\section{Polarización}

Entre los vectores que conducen a procesos de polarización, el enfoque de ventanas rotas (broken windows approach) alude a los imaginarios de falta de estructuras y control social que evoca el deterioro físico y la obsolescencia urbana, y esto fomenta el temor de los ciudadanos a salir de sus casas (Wilson \& Kelling, 1982). La privacidad como un principio rector e incuestionable del diseño urbano o el espacio defendible de Chermayeff y Alexander (1973) transforma el espacio urbano en numerosas jerarquías de control espacial. Newman (1972) apela a la supuesta territorialidad animal, para enunciar que cualquier otra persona es potencialmente peligrosa, lo que obliga a protegerse desde el espacio interior. La búsqueda de seguridad transforma el espacio urbano con intervenciones anticipadas para intensificar el control social mediante diferentes medidas sociopolíticas y de carácter policial y penal (Dinges \& Sack, 2000; Wehrhahn y Haubrich 2010). La 
expectativa de un acto criminal está determinada por la propia experiencia (victimización personal o directa), o por modelos de observaciones e informaciones de terceros que aparecen creíbles (victimización indirecta) (Lüdemann, 2006; Wehrhahn \& Haubrich, 2010). La victimización explica la espera ante la probabilidad subjetiva de ocurrencia de una experiencia (amenazante) con alguien y en un espacio en particular.

Beck (2002) plantea que la globalización capitalista y sus efectos, ha desestructurado modelos de organización, de regulación y de relaciones políticas y sociales más o menos ya asimilados, con sus seguridades $y$ sus miedos conocidos, de allí que el riesgo proviene de muchos frentes, desde el natural hasta el geopolítico, y en dimensión escalar. Con frecuencia los miedos ciudadanos no son próximos, ni predecibles ni controlables. El miedo puede materializarse en cualquier ciudad, y no resulta tan solo de esta materialización sino de la posibilidad de que sea, de la vulnerabilidad, de la psicosis o de la paranoia. $\mathrm{Y}$ todos estos argumentos y motores para el miedo, como se ha dicho, tienen su espacialización (Beck, 2002). Molina (2001), a su vez, desarrolla el enfoque de racialización como el proceso que lleva a individuos e instituciones de una sociedad determinada a pensar, actuar y a ejercer discriminación en la ciudad a partir de un ideario de pertenencia racial. La clausura de identidad opera territorialmente frente a un sujeto que denota peligro en tanto cuerpo humano sexuado, perteneciente a una cierta clase social y racializado (Garner, 2010). Un indicador de 'mutación' en la dinámica de la diferenciación socioespacial es la dimensión de escala geográfica. La segregación socioespacial se ha caracterizado por distancias geográficas que separan los grupos distintos, grandes extensiones de conjuntos habitacionales homogéneos en pobreza y en una estructura urbana aislada y precaria en la periferia. Las nuevas estructuras urbanas, resultado de la gestión inmobiliaria, evidencian otro tipo de fenómeno. Con la cercanía geográfica entre grupos socioeconómicos distintos, la segregación socioespacial desdibuja sus dimensiones generando nuevas formas de diferenciación; así también en las áreas centrales, los procesos de transformación socioespacial están afectando la vida de las comunidades locales, especialmente de aquellos más vulnerables o con menos capacidad económica.

\section{El barrio "emergente" en términos genéricos}

Sus límites hacen evidente el proyecto inmobiliario con monodiseño arquitectónico habitacional (vivienda o edificios), con pasajes estrechos, pocas avenidas, mobiliario urbano, jardines, luminarias, entre otros, conforman los espacios públicos. La homogeneidad constructiva y la trama del barrio le dan un aspecto artificial en el entramado urbano, sin ligazón explícita a los flujos del tejido socioespacial. El barrio emergente parece no tener imageability (Lynch, 1971) ya que por el carácter homogéneo de su estructura, sus componentes físicos y lugares no son tan identificables por sus residentes, ni apropiados por ellos. Desde la perspectiva territorial, el barrio emergente es un "adjunto", pertenece a sus residentes, no se conecta más allá de sus límites. Es un conjunto cerrado, que forma parte de un modelado urbano fragmentado, que convive por medio de subcentros funcionales, que otorgan la nota diversa a las suburbanizaciones. El barrio emergente es discutible desde la perspectiva de la sustentabilidad urbana barrial, como área urbana que interactúa con el medio físico, social y económico, en una dimensión espacio-temporal. Estos barrios han estado experimentando transformaciones en el tiempo y en su estructura, por el bloqueo de bienes nacionales de uso público con rejas y sistemas de vigilancia que se ilustran en el ejemplo del Parque Violeta Cousiño.

\section{El "consumo" de vivienda en el contexto neoliberal chileno y latinoamericano: una cuestión de forma}

En el Chile del siglo XX, la vivienda ha sido uno de los ámbitos políticos más importantes, en la medida en que prácticamente todos los gobiernos de turno le han brindado especial atención, aunque con diversos niveles de éxito, y a pesar de que las condiciones de vivienda para los más pobres han mejorado con el correr de los años, el problema nunca ha sido resuelto satisfactoriamente 
(Molina y Galleguillos, 2006). El régimen autoritario de Pinochet (1973-1989) utilizó el tema de la vivienda social como instrumento político, implementando diversos programas de vivienda social, abiertamente cuestionables desde su calidad constructiva y calidad de vida. El extenso programa de Erradicación de Campamentos que el régimen inició en 1979, significó el traslado de familias pobres desde las comunas de altos ingresos donde vivían en tomas y conjuntos de viviendas sociales, a diversas comunas, con el doble fin de erradicar los focos de pobreza de las comunas de altos ingresos, y disgregar al colectivo de pobladores que existía (Molina, 1985; Morales y Rojas, 1986). Entre 1979 y 1984, más de 26.000 familias fueron erradicadas desde un total de 65 campamentos, hacia viviendas sociales definitivas. Este programa fue el principal causante de las profundas trans- formaciones socioespaciales en Santiago, con las correspondientes consecuencias sociales, económicas, políticas y ambientales que se generaron como producto de una planificación urbana intencionalmente excluyente. Los hechos muestran que en el caso de Chile, como también en otros casos, la segregación socioespacial fue provocada por las políticas urbanas de erradicación y fundación de nuevas comunas a objeto de homogeneizar socialmente la población (Molina, 1985; Galleguillos, 2007).

\section{El Gran Santiago y la estructura urbana}

Apoyándose en los modelos clásicos norteamericanos sobre estructura urbana -zonas concéntricas de Park et al. (1925), sectores de Hoyt (1939) y multinuclear de Harris y Ullman (1945), así como en las investiga-

Figura $N^{\circ} 1$

Modelos de estructuras urbanas para ciudades latinoamericanas y para el Gran Santiago

\section{A. Modelo Bähr y Riesco (1981)}

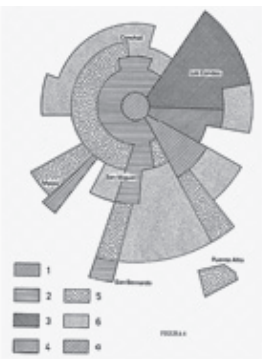

B. Modelo Janoschka (2002)

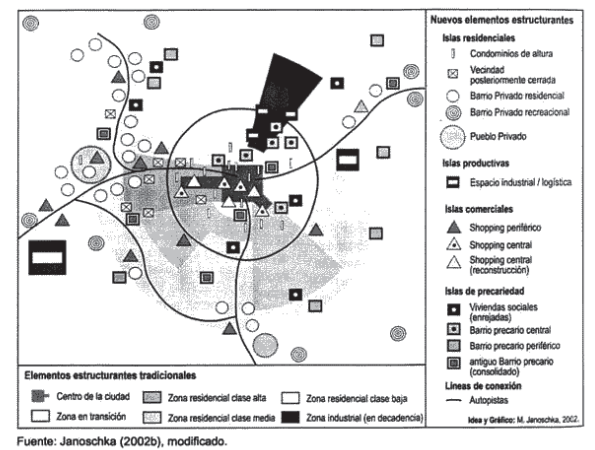

C. Modelo de Cuadrantes para Santiago (Inzulza 2009)

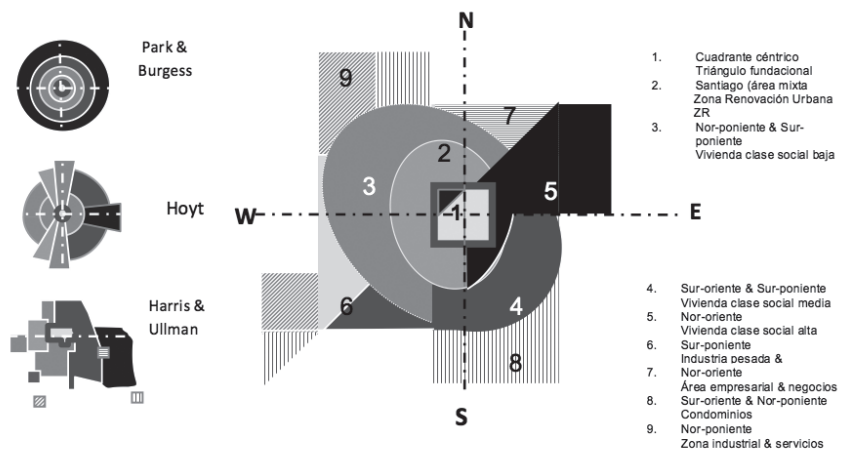

Fuente: Bähr y Riesco (1981), Janoschka (2002), Inzulza, (2012a). 
ciones de Bähr y Riesco (1981) y Janoschka (2002)-, se esboza un Modelo de Cuadrantes para el Gran Santiago (MCS) (ver Figura № 1) que ayuda a la comprensión de la configuración tipológica y topológica del crecimiento urbano. Actualmente, se identifica una fase histórica de crecimiento en zonas concéntricas desde el centro histórico hasta el anillo de la circunvalación Américo Vespucio). El modelo de síntesis MCS (Inzulza, 2009) permite distinguir cuatro áreas relacionadas con subcentros o núcleos suburbanos resultado del acelerado crecimiento demográfico desde 1960 hasta el presente siglo. Al mismo tiempo, permite visualizar nueve sectores que determinan la estructura y forma urbana, comenzando por el área fundacional, una "grilla cuadriculada" ( $N^{\circ} 1$ en Figura $N^{\circ}$ 1.C), que se fue extendiendo desde este centro hacia las áreas periféricas. Aunque esta cuadrícula, herencia del modelo español, ha ido desdibujando su forma original, o adquiriendo nueva forma, de acuerdo a modelos históricos de crecimiento urbano, aun se visualiza la matriz de referencia de la ciudad en el territorio.

Por su parte, el anillo pericentral de la ciudad constituye el área urbana consolidada de Santiago, con usos de suelos principalmente industriales y comerciales de mayor escala. Allí se encuentra la principal zona de renovación propuesta por el Ministerio de Vivienda y Urbanismo ( $\mathrm{N}^{\circ} 2$ en Figura $\mathrm{N}^{\circ}$ 1.C) con predominancia de vivienda social (estratos de bajos ingresos) ( $\mathrm{N}^{\circ} 3$ en Figura $\mathrm{N}^{\circ}$ 1.C). Los dos anillos viales principales, sugieren como en el modelo de zonas concéntricas de Park y Burgess (1925) la generación de fenómenos de presión de cada zona circular consolidada para sus residentes y el uso de suelo que ellos representan en la zona circular adyacente ubicada más afuera (Balchin et al., 1988). De esta forma, el MCS muestra además una configuración en clusters de pobreza en áreas periféricas, aunque las principales áreas de vivienda social se localizaban históricamente en los cuadrantes norponiente y surponiente. Por otra parte, en los cuadrantes nororiente y suroriente de la ciudad, se localizan conglomerados de vivienda de clase media ( $N^{\circ} 4$ en Figura $\left.N^{\circ} 1 . C\right)$ y clase alta $\left(N^{\circ}\right.$ 5 en Figura $N^{\circ}$ 1.C).

Estos conglomerados traspasan el anillo vial mayor localizándose en áreas con alta calidad de infraestructura urbana y relación con el medio natural. En el cuadrante suroriente, y gran parte del cuadrante surponiente, se localizan clusters de vivienda de estratos medios en suelo urbano de mejor calidad (4 en Figura $N^{\circ}$ 1.C), coincidiendo con límites geográficos como ríos, relieves, líneas ferroviarias, u otros identificadores de Hoyt (1939). Esta misma condición se encuentra además en clusters de vivienda para clase alta ubicados en el cuadrante nororiente (5 en Figura $N^{\circ}$ 1.C) donde se localizan "clusters habitacionales distintos y segregados entre ellos" (Shafer, 1977: 132). Más allá de la Circunvalación A. Vespucio se identifican dos patrones principales de usos de suelo, industria y manufactura $\left(\mathrm{N}^{\circ} 6\right.$ en Figura $\mathrm{N}^{\circ}$ 1.C) localizada en el cuadrante suroriente, $y$ negocios en el cuadrante nororiente $\left(\mathrm{N}^{\circ} 7\right.$ en Figura $\mathrm{N}^{\circ}$ 1.C). Asimismo, se advierten nuevos usos de suelo urbano con proyectos tipo condominios ( $\mathrm{N}^{\circ} 8$ en Figura $\mathrm{N}^{\circ}$ 1.C) en los cuadrantes suroriente y norponiente. Los centros urbanos localizados en comunas como Colina, Lampa, Puente Alto y Quilicura "son conectados por rutas de transporte mayor que atraviesan áreas de desarrollo considerable por fuerzas económicas centrales de la comunidad" (Shafer, 1977: 130). Finalmente, en los cuadrantes norponiente y surponiente se ubica un sector caracterizado por usos industriales y servicios ( $\mathrm{N}^{\circ} 9$ en Figura $\mathrm{N}^{\circ}$ 1.C) evidenciando el rol de la ciudad como núcleo de negocios, cuya forma predominante es resultado del proceso de globalización contemporánea.

\section{El mercado de la vivienda en Santiago de Chile}

Como se puede apreciar también en el modelo de Janoschka (2002) para la ciudad latinoamericana, la ciudad de Santiago ha experimentado una gran metamorfosis, particularmente a mitad del siglo XX, cuando la explosión demográfica la posicionó como el principal centro urbano chileno, con las problemáticas y complejidades que conlleva ese rol (Sabatini y Arenas 2000). Se puede reconocer la extensión como la principal política para enfrentar el crecimiento de Santiago. En menor grado, programas de renovación urbana del Estado en el centro y vivienda social en la periferia en casi todas las direcciones de la ciudad (Ducci, 2002; Rocha et 
al., 2001, 2005; Daher, 1991). Como resultado de ello, Santiago viene experimentando grandes transformaciones socioespaciales (Gurovich, 2000; Galleguillos, 2012). La influencia de la globalización como fenómeno vigente desde los 90 con cambios en los patrones de vida urbana y tendencias del uso de suelo, han creado problemas adicionales a la identidad original y tipo de vida local que el área central del Gran Santiago mostraba hasta hace pocas décadas, especialmente en sus barrios más antiguos (Contreras, 2011; Fuentes y Sierralta, 2004; De Mattos, 1999, 2002). A esta fase de extensión, le ha seguido una fase de densificación en áreas consolidadas y centro histórico que se mantiene en la actualidad. Las políticas urbanas enmarcadas en la economía neoliberal, desde los inicios de los 80 promovieron una mayor inversión en el suelo urbano, con una significativa expansión de la actividad inmobiliaria, especialmente acrecentada en los últimos treinta años a través de subsidios de renovación urbana que entregaron amplios beneficios al desarrollo del sector privado (Arriagada et al., 2007; Valenzuela, 2004). Las estadísticas de MIDEPLAN (2000), muestran un impacto en la tenencia de la vivienda del "Gran Santiago" con un $67,91 \%$ de los hogares como propietarios versus un 13,07\% como arrendatarios para el año 2002 (998.063 propietarios y 193.654 arrendatarios de un total de 1.489.645 hogares).

El Cuadro $\mathrm{N}^{\circ} 2$ sintetiza esta tendencia en las tipologías de casas y departamentos. La categoría de 'casas' incluye las edificaciones de fachada continua, pareada y aislada, emplazada en terrenos individuales o parte de un terreno en común o condominios. La otra categoría, 'departamentos', corresponde a edificios de altura media o de altura, pudiendo ser parte de un condominio. Durante el periodo 1992-2002, se constató un fenómeno de localización territorial diferencial en altura por el aumento de 53.591 departamentos (75\%) en el cuadrante nororiente (de 71.407 a 124.998 unidades), ubicando ese sector en la cima de la lista de ventas de propiedades y, además, representando casi un $40 \%$ del total de departamentos del Gran Santiago en 2002. En el centro de la ciudad, se advierte una situación similar, con 38.661 departamentos en 2002 , representando un aumento del 70,3\% (comuna de Santiago). En la categoría 'casas', en todo el Gran Santiago se verifica un alza, exceptuando la comuna centro, con un aumento entre el 2,6\% (cuadrante nororiente) y el $31,9 \%$ (cuadrante surponiente). Sin embargo, este aumento es menos significativo considerando el incremento en departamentos en edificios de altura media y altura en el mismo periodo ( $73 \%$ en promedio).

Solo en el centro de la ciudad (comuna de Santiago), la oferta de propiedades al año 2008 produjo una densificación, mostraba un número de 50 edificios-departamentos en altura en venta. Arquitectónicamente, la mayoría de estos proyectos son diseñados sin balcones o terrazas en altura y en base a estructuras de formas compactas como esbeltos

Cuadro $\mathrm{N}^{\circ} 2$.

Tipología de vivienda en el Gran Santiago, 1992-2002

\begin{tabular}{|c|c|c|c|c|c|c|c|c|c|}
\hline \multirow{2}{*}{ Cuadrante } & \multicolumn{3}{|c|}{ Total viviendas } & \multicolumn{3}{|c|}{ Casas } & \multicolumn{3}{|c|}{ Departamentos } \\
\hline & 1992 & 2002 & $\%$ & 1992 & 2002 & $\%$ & 1992 & 2002 & $\%$ \\
\hline Nororiente & 193.576 & 236.287 & 22,0 & 106.117 & 108.949 & 2,6 & 71.407 & 124.998 & 75,0 \\
\hline Norponiente & 279.516 & 314.096 & 12,3 & 209.230 & 253.923 & 21,3 & 22.533 & 39.466 & 75,1 \\
\hline Suroriente & 346.199 & 423.791 & 22,4 & 259.934 & 340.347 & 30,9 & 36.671 & 64.937 & 77,0 \\
\hline Surponiente & 273.767 & 344.931 & 25,9 & 214.501 & 283.077 & 31,9 & 22.344 & 46.953 & 70,1 \\
\hline $\begin{array}{l}\text { Centro de } \\
\text { Santiago }\end{array}$ & 63.204 & 67.331 & 6,5 & 28.510 & 24.146 & 15,3 & 22.690 & 38.661 & 70,3 \\
\hline Gran Santiago & 1.156 .262 & 1.385 .436 & 18,8 & 818.292 & 1.010 .442 & 23,4 & 175.645 & 315.015 & 79,2 \\
\hline
\end{tabular}

Fuente: elaboración propia basada en INE (1992-2002). 
paralelepípedos, emplazados desde el nivel subterráneo del predio, tratando de maximizar la superficie construida para aprovechar las condiciones de edificación establecidas en el plan regulador comunal. Además, se diseñan como espacios con acceso controlado, cámara de seguridad con circuito cerrado y sistema de administración local privada (condominios en altura). De esta forma, es posible obervar un creciente fenómeno de diferenciación territorial para el Gran Santiago, producto de la gestión de negocios inmobiliarios y su oferta hacia grupos de nuevos residentes que llegan a vivir al centro, pericentro y periferia de la ciudad, como santiaguinos gentrificadores. El área del cuadrante nororiente y especialmente el centro de la ciudad al parecer son las zonas más atractivas para localización de vivienda nueva en altura (Serex, 2002), mientras que la periferia recibe condominios en baja altura y que en muchas ocasiones terminan como áreas enrejadas (ver ejemplos en Figura $N^{\circ} 2$ ).

La interpretación contemporánea de los modelos urbanos clásicos de Burgess, Harris, Hoyt, y que esquematizan las ciudades (norteamericanas) desde inicios del siglo XX hasta los años sesenta como espacios diferenciales, pero contiguos, integrados y referenciados alrededor de un centro, es en cambio, como se muestra en este análisis, y como lo afirman Bähr y Riesco (1981), Soja (2000) y Janoschka (2002), la imagen urbana de la fragmentación de funciones y grupos que generan una terri- torialidad antagónica, la postmetrópolis (Soja, 2000). Los fenómenos de diferenciación socioespacial tienen su expresión física en estas transformaciones cuyos efectos ya fueron revisados. Actualmente, muchos de los efectos que se observan en el Gran Santiago se atribuyen en una buena mayoría al miedo y la búsqueda de la seguridad que al parecer es el vacío más predominante que caracteriza esta nueva configuración de la morfología urbana (Garreau, 1991; Ascher ,1995; Smith, 1996; Harvey, 2004; Vicente, 2003). Las gated cities urbanizaciones cerradas (Ellin, 1996, 1997), las ciudades borde, edge cities, como las define Garreau (1991) y la privatopía para describir el presente urbano y ciudadano (Borja y Castells, 1997; Borja, 2003). Examinar estos procesos para lograr una mayor comprensión de sus particularidades y sus vinculaciones e implicancias en el contexto latinoamericano y en el ejemplo de Santiago de Chile constituye el propósito de este análisis contextual teórico y empírico.

\section{Aplicación metodológica Análisis contextual empírico: tipología y topología centro-periferia}

El análisis contextual empírico de los fenómenos de gentrificación y segregación, se articula con el análisis contextual teórico, examinando dos tipos de estructuras urbanas barriales en Santiago de Chile por medio de observación participante directa y vinculante. Se seleccionan dos barrios: El Llano Suberca-

Figura $\mathrm{N}^{\circ} 2$

Vivienda en altura (pericentro) y baja altura (periferia) en el Gran Santiago. A. Barrio El Llano Subercaseaux; B. Barrio Parque Violeta Cousiño.
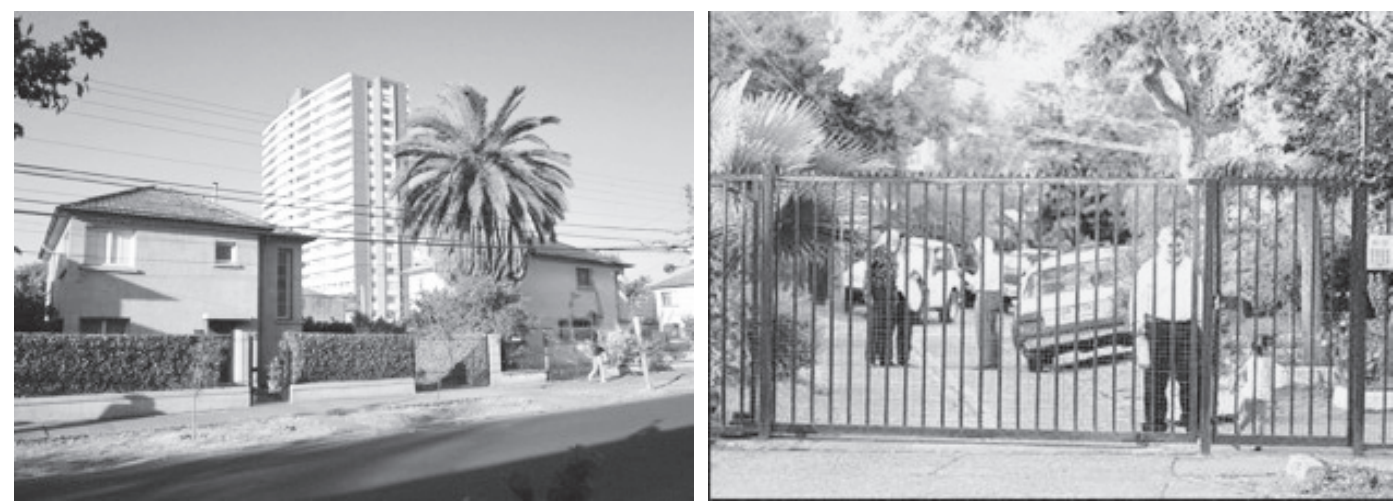

Fuente: Archivo personal de los autores. 
seaux por caracterizarse como barrio pericentral histórico localizado en la comuna de San Joaquín, y Parque Violeta Cousiño por caracterizarse como barrio periférico emergente de la comuna de Peñalolén. Los resultados son sistematizados en una matriz tipológica y topológica para hacer emerger las distinciones de forma y procesos relevantes en la relación entre las estructuras barriales resultantes.

\section{Latino gentrificación y polarización en Santiago de Chile}

¿Qué efectos tipológicos y topológicos se pueden reconocer en el pericentro histórico y en la periferia producto de las transformaciones socioespaciales barriales? La hipótesis plantea en el ejemplo del barrio pericentral histórico El Llano Subercaseaux y Parque Violeta Cousiño en Peñalolén en la periferia "emergente", que los efectos de las transformaciones socioespaciales en el espacio urbano de Santiago de Chile, tienden a generar estructuras socioespaciales de tipo latino gentrificación y polarización. Estos procesos de cambio se revisan poniendo al barrio en la perspectiva de la ciudad. Para una mayor comprensión de las particularidades y vínculos de estos procesos con el entorno urbano la matriz tipológica y topológica sistematiza los cambios observados en los barrios. La diferenciación social es un fenómeno cambiante que genera un sistema de actuaciones que reflejan múltiples formas de discriminación. Las diferentes categorías de discriminación, construidas social y culturalmente se crean y potencian unas a otras (pobreza, racismo, sexismo, discriminación religiosa o por nacionalidad, orientación sexual, clasismo y discapacidad) interactúan en simultáneos niveles y espacialidades, contribuyendo a una sistemática desigualdad social, que transforma las estructuras urbanas barriales adaptándolas según reglas de poder, y manteniendo las desigualdades sociales.

\section{El barrio pericentral histórico Llano Subercaseaux}

En Santiago de Chile, las estructuras urbanas barriales, desde sus inicios y, desde las primeras zonas de expansión hacia el norte y sur de la ciudad, constituyeron un significativo legado de habitabilidad, con vivienda en baja altura de gran calidad arquitectónica asociada a un entorno urbano-rural que permitía al santiaguino encontrarse con sus pares, pasear en sus calles locales, contemplar los hitos naturales (cerros y cauces fluviales) y vivir en un entorno inmediato integrado a una escala humana. Este escenario barrial ha experimentado un acelerado ritmo de transformaciones. Este acelerado proceso de cambio en las estructuras barriales se relaciona con la aplicación de las políticas urbanas en favor de la liberalización del mercado y de una mayor inversión inmobiliaria con incentivos económicos directos en el suelo urbano, produciendo transformaciones en los patrones físicos y sociales del habitar barrial (Shafer, 1997). Así, las políticas urbanas provocaron impacto en el precio del suelo, modificando los patrones de uso de suelo hacia la periferia y en el tejido urbano por el crecimiento en extensión (Sabatini y Arenas, 2000; Becerril-Padua, 2000), cuyo resultado es una estructura urbana diferenciada en clusters socioespacial de altos, medianos y bajos ingresos. Precisamente en el barrio El Llano Subercaseaux, la sustitución de edificación existente de fachada continua o pareada, de uno, dos o tres pisos, de uso principalmente (u originalmente) residencial por una nueva tendencia de residencia con vivienda en mediaaltura y altura, más que el desplazamiento de clases obreras, o de menores ingresos hacia la periferia de la ciudad por clases de altos ingresos, o el retorno de clases de ingresos medios y altos al centro de la ciudad para establecerse con actividades artístico-culturales, característico de procesos de gentrificación, predomina en las transformaciones socioespaciales barriales, de tal modo según Inzulza (2012a, 2012b) esta distinción corresponde a una forma particular de latino gentrificación.

\section{El barrio periférico emergente Parque Violeta Cousiño en Peñalolén}

La política de homogeneización social a través de la comunalización de Santiago (1982-1984), generó en esta comuna de habitantes pobres, una estructura urbana fragmentada en comunas ricas y pobres, donde la dimensión de la diferenciación social estaba dada por grandes distancias geográficas que separaban estos grupos socioeconómicos, grandes extensiones homogéneas en forma y pobreza, la segregación socioespacial (Galleguillos, 2007). En las últimas décadas 
este patrón de diferenciación socioespacial fue modificado por la inversión inmobiliaria, que ha sido el actor central en el desarrollo urbano. La estrategia inmobiliaria para atraer estratos medios y altos a comunas estigmatizadas por la pobreza fue quebrar el umbral crítico del estigma, con enormes proyectos inmobiliarios para residentes de estratos medios y altos, como es el caso de Peñalolén. La nueva estructura se caracteriza por barrios socioeconómicos distintos, cercanos, separados por una vía. La observación de este fenómeno generó variadas hipótesis acerca de las implicancias de esta cercanía para los grupos socioeconómicos involucrados. La cercanía traería beneficios a ambos grupos sociales, la destrucción del estigma de la pobreza y la integración social, pero también la expulsión paulatina de los habitantes por especulación (Sabatini y Arenas 2000; Galleguillos, 2007). Con el tiempo, se observan marcas que indican que esta cercanía entre grupos distintos constituye una realidad compleja y no exenta de conflictos y transformaciones socioespaciales. Además, las respuestas comunitarias frente a la cercanía, responden a imaginarios que no necesariamente se sitúan en la cercanía, pero donde la presencia de la pobreza los hace presente (CIPER, 2010). Estos signos muestran un tránsito de un fenómeno de segregación a un fenómeno de polarización social de origen global y local.

Para constatar este hecho, una paradoja: allí donde antes las estructuras socioespaciales eran homogéneas en pobreza, los promotores inmobiliarios encontraron inmejorables cualidades de habitabilidad: vivir en una localización adecuada en distancia geográfica y un entorno ambiental cualitativamente mejor respecto de otros sectores y del centro contaminado de Santiago. Las comunas periféricas comenzaron a ser vistas por los promotores inmobiliarios como fuentes de negocios lucrativos para satisfacer la demanda de vivienda de una clase media en expansión y con acceso al correspondiente crédito bancario. He aquí el motor de la polarización social entendida como el proceso por el cual en un conjunto originariamente indiferenciado se establecen características o rasgos distintivos que determinan la aparición en él de dos o más zonas mutuamente diferenciadas socioeconómicamente. Alrededor del año 2000, el desarrollo inmobiliario de la comuna de Peñalolén se centró en los antiguos terrenos de la Viña Cousiño, desencadenando un crecimiento acelerado de conjuntos habitacionales para clases media-altas. Si bien estos conjuntos se construyeron bajo la lógica de conjuntos habitacionales, varios de ellos, controlaron los accesos al punto de parecer grandes condominios que quedaban aislados del resto de la comuna, tanto en el diseño con sus intrincados pasajes, como con soluciones más drásticas como el enrejamiento de sus perímetros en los conjuntos que quedaban más expuestos a Avenida Grecia.

En los primeros años de estas transformaciones comunales, los pobladores, especialmente las mujeres, percibieron y valoraron las ventajas de esta cercanía. Las mujeres valoraron la disminución en sus tiempos de viaje al trabajo, ya que la cercanía favoreció el encontrar empleos cerca. También los tiempos de viaje para hacer compras disminuyeron, por el aumento de los centros de servicios con suficiente equipamiento comercial y de servicios, y mayores comunicaciones. La tendencia a "quedarse dentro de los límites de la población" cambió frente a la cercanía geográfica con urbanizaciones de habitantes de mayores ingresos. Esta estructura parecía favorecer los contactos fuera de sus límites, contactos que también tenían como sentido el mejorar su situación socioeconómica (GaIleguillos, 2007). La paradoja es que lo que parecía un signo de convivencia entre grupos distintos, en la actualidad se ve enfrentado a un fenómeno de aumento del cierre de calles y pasajes con el propósito de generar una mayor seguridad ciudadana. El Parque Violeta Cousiño es un ejemplo de progresivo cierre de calles y pasajes, que aunque dentro de un marco de ilegalidad, continúa siendo una práctica. Los vecinos del sector, a favor de la reja, argumentan que se sienten más protegidos con sus calles cerradas. El cierre de los pasajes de todo el sector que da hacia Av. Grecia, encubre un sentimiento de temor hacia los barrios pobres que se encuentran al frente de estos nuevos conjuntos, pero más por lo que representan, que por lo que realmente constituyen como comunidad (CIPER, 2010). La amenaza no tiene una dirección exacta, sino viene de todas partes (Beck, 2002), y además acentuada por una sensación de abandono de las estructura sde derecho del Estado. Un vecino alude así a la 
pérdida del espacio público emblemático del Parque Violeta Cousiño:

“...es el caso del Parque del mismo nombre Violeta Cousiño, el que supuestamente nos lo vendieron como que pertenecía a la urbanización, y que posteriormente fue destruida para dar cabida a otro proyecto de viviendas en altura" (vecina de dentro del barrio P.V.C.).

El cierre de pasajes crea una ilusión de seguridad aparente a los vecinos pero contribuye a la generación de resentimiento social.
Además las rejas aumentan el sentimiento de inseguridad cuando se está fuera de ellas:

"Cualquier persona que suba por la Avenida Grecia, después de Tobalaba, puede ver cómo los vecinos han ido privatizando las calles que salen a esa avenida poniendo rejas. La Municipalidad sabiendo de la ilegalidad de esta actitud hace oídos sordos y permite esta violación a uno de los derechos básicos de todo chileno: La libre circulación por las calles, que son patrimonio entero de la ciudadanía. Por las noches la cosa se pone más complicada ya

Cuadro $\mathrm{N}^{\circ} 3$

Matriz tipológica y topológica pericentro-periferia

El Llano Subercaseaux: Sustitución de edificación existente de fachada continua o pareada, de uno, dos o tres pisos, de uso principalmente (u originalmente) residencial por una nueva residencia con vivienda en media-altura y altura, predomina en las transformaciones socioespaciales barriales, de tal modo se confirma la tendencia observada por Inzulza (2012; 2012b) y cabe hacer la distinción de latino gentrificación para el proceso que ocurre en el pericentro histórico.

\begin{tabular}{|c|c|c|}
\hline Proc & Detonantes y & ¿Se \\
\hline $\begin{array}{l}\text { Latino gentrificación } \\
\text { pericentro }\end{array}$ & $\begin{array}{l}\text { Inversion privada } \\
\text { Edificios } \\
\text { Especulación dejando al } \\
\text { abandono inmuebles patri- } \\
\text { moniales } \\
\text { Invasión } \\
\text { Densificación } \\
\text { Congestión } \\
\text { Estagnación obsolescencia } \\
\text { Penumbra } \\
\text { Pérdida de vista de la forma } \\
\text { urbana } \\
\text { Desequilibrio entre renova- } \\
\text { ción y conservación patri- } \\
\text { monial } \\
\text { Polarización } \\
\text { Transformación estilos de } \\
\text { vida } \\
\text { Victimización } \\
\text { Autoconfinamiento (nuevos) } \\
\text { Pérdida de identidad }\end{array}$ & $\begin{array}{l}\text { Regular Inversión privada } \\
\text { Detener construcción de Edificios } \\
\text { Neutralizar especulación } \\
\text { Transformar invasión en recursos humanos ba- } \\
\text { rriales } \\
\text { Detener Densificación } \\
\text { Enfrentar congestión con medidas no conven- } \\
\text { cionales participativas } \\
\text { Intervenir la obsolescencia física con medidas } \\
\text { no convencionales participativas } \\
\text { Enfrentar penumbra que provocan edificios en } \\
\text { edificaciones originales del barrio como discri- } \\
\text { minación y regular altura de edificaciones } \\
\text { Tomar en alta consideración la forma urbana y } \\
\text { desarrollar un concepto para el pericentro } \\
\text { Lograr equilibrio entre renovación y conserva- } \\
\text { ción patrimonial } \\
\text { Integración vecinal para reducir la polarización } \\
\text { Transformación sustentable de los estilos de vida } \\
\text { Neutralizar Victimización } \\
\text { Evitar seclusión de vecinos nuevos y antiguos } \\
\text { Desarrollar medidas para recuperar identidad }\end{array}$ \\
\hline \multicolumn{3}{|c|}{$\begin{array}{l}\text { Parque Violeta Cousiño: Lo que parecía convivencia entre grupos distintos, enfrenta un aumento del } \\
\text { cierre de calles y pasajes por seguridad. Estas marcas indican que la cercanía entre grupos distintos no } \\
\text { está exenta de conflictos. Además, la comunidad se cohesiona en función de imaginarios globales de } \\
\text { miedo, riesgo y amenaza, pero donde la cercanía de la pobreza los personaliza (CIPER 2010). Estos } \\
\text { signos muestran un tránsito de un fenómeno de segregación socioespacial a un fenómeno de polariza- } \\
\text { ción social en estructuras urbanas fragmentadas. }\end{array}$} \\
\hline
\end{tabular}


Continuación Cuadro $N^{\circ} 3$

\begin{tabular}{|c|c|c|}
\hline Proceso & Detonantes y efectos & ¿Se puede contrarrestar los efectos? \\
\hline $\begin{array}{l}\text { Polarización peri- } \\
\text { feria }\end{array}$ & $\begin{array}{l}\text { Inversión privada } \\
\text { Casas y edificios } \\
\text { Especulación con terrenos } \\
\text { agrícolas } \\
\text { Cercanía grupos socioeconó- } \\
\text { micos distintos } \\
\text { Densificación } \\
\text { congestión } \\
\text { Pérdida de vista de la forma } \\
\text { urbana } \\
\text { Desequilibrios entre desa- } \\
\text { rrollo urbano sustentable y } \\
\text { gestión inmobiliarial } \\
\text { Polarización } \\
\text { Transformación estilos de } \\
\text { vida } \\
\text { Victimización (nuevos) } \\
\text { Autoconfinamiento (nuevos) } \\
\text { Seclusión social (nuevos) } \\
\text { Barrio sin identidad } \\
\text { rejas }\end{array}$ & $\begin{array}{l}\text { Regular Inversión privada } \\
\text { Detener enrejamiento de BNUP en conjuntos de } \\
\text { Casas y edificios } \\
\text { Detener Especulación inmobiliaria en terrenos } \\
\text { agrícolas } \\
\text { Fomentar la cercanía de grupos socioeconómi- } \\
\text { cos distintos } \\
\text { Establecer medidas frente a la Densificación } \\
\text { Establecer medidas frente la congestión } \\
\text { Desarrollar un concepto urbano periférico que } \\
\text { recupere la integración urbana también en la } \\
\text { forma } \\
\text { Enfrentar los desequilibrios entre desarrollo ur- } \\
\text { bano sustentable y gestión inmobiliaria } \\
\text { Enfrentar el fenómeno de polarización con me- } \\
\text { didas participativas } \\
\text { Transformación sustentable de los estilos de vida } \\
\text { Neutralizar la victimización (nuevos y antiguos) } \\
\text { Neutralizar el Autoconfinamiento y Seclusión } \\
\text { social de nuevos y antiguos vecinos } \\
\text { Promover una identidad comunal, rompiendo } \\
\text { los límites físicos impuestos por las propias co- } \\
\text { munidades cohesionadas en torno al miedo. }\end{array}$ \\
\hline
\end{tabular}

Fuente: Elaboración propia.

que las entradas se reducen y para ingresar a estos conjuntos habitacionales uno debe desplazarse hasta 15 cuadras. Hablo de el conjunto habitacional parque Violeta Cousiño" (vecina de fuera del barrio P.V.C.).

\section{Matriz tipológica y topológica}

La triangulación téorica y empírica se articula examinando dos tipos de estructuras urbanas barriales en terreno: Dos barrios: El Llano Subercaseaux, barrio pericentral histórico localizado en la comuna de San Joaquín, y Parque Violeta Cousiño, barrio periférico emergente de la comuna de Peñalolén. Los resultados de las observaciones en terreno, son sistematizados en una matriz tipológica y topológica que pretende visibilizar las distinciones de cada barrio. La matriz relaciona las estructuras barriales resultantes. Respecto del centro histórico, la sustitución de edificación existente de fachada continua o pareada, de uno, dos o tres pisos, de uso principalmente (u originalmente) residencial por una tendencia de residencia con vivienda en media- altura y altura, son elementos predominantes en el proceso que se distingue como latino gentrificación que transforma la vida barrial. En el caso de fenómenos de diferenciación socioespacial de tipo polarización, como se muestra en el ejemplo de Parque Violeta Cousiño, la distinción más evidente es esta percepción que lleva a miles de vecinos en las comunas más pobladas de Santiago a organizarse cerrando más de 800 calles y pasajes, aunque medida ilegal (las vías cerradas por los residentes se concentran en Maipú, Peñalolén y La Reina) (El Mercurio, 2009a, $2009 b)$. Esta percepción no tiene un correlato consecuente con los índices de riesgo objetivo en Chile (Paulsen 2008; Dammert et al., 2003). La territorialización del delito hace que disminuya el capital simbólico de las personas que ya son objeto de diferenciación socioespacial, incrementando el capital simbólico de aquellas más favorecidas por el orden socioeconómico del país (Bauman, 2011, 2006; Galleguillos, 2012). En esto, la televisión y los medios de comunicación contribuyen en gran medida al reforzamiento del 
fenómeno en nuestras ciudades al aplicar una operación de reducción consistente en clausurar la identidad de las personas en torno a su pertenencia territorial (Martínez, 2006). En este sentido constituye un rasgo topológico y tipológico del barrio periférico emergente, como se puede observar en la matriz.

\section{Discusión y conclusiones}

Los hallazgos muestran para los procesos de transformación socioespacial barrial pericentral y periférico, una fase de latino gentrificación y polarización. Esto significa que la segregación ha mutado hacia polarización en un escenario de cercanía geográfica donde la pobreza y la desarticulación espacial generan bloqueo de la relación entre vecinos. Respecto del centro histórico, la sustitución de edificación existente de fachada continua o pareada, de uno, dos o tres pisos, de uso principalmente (u originalmente) residencial por una tendencia de residencia con vivienda en media-altura y altura, más que el desplazamiento de clases obreras, o de menores ingresos hacia la periferia de la ciudad por clases de altos ingresos, son elementos predominantes en el proceso que se distingue como latino gentrificación. En estos barrios, el gran perdedor frente a estos procesos de transformación es el espacio público. Lo que es más cívico dentro de la ciudad genera inseguridad, los espacios públicos. Del parque se pasa al pequeño jardín privado, de la plaza al centro comercial o al country club, de la calle a las galerías, de la policía al guardia de seguridad, del barrio a la urbanización cerrada, etcétera. De manera que lo público queda como residual, no deseado y al servicio de quien no tiene otra alternativa.

Lo que parecía convivencia entre grupos distintos, en Parque Violeta Cousiño enfrenta un aumento del cierre de calles y pasajes. Estas marcas indican que la cercanía entre grupos distintos no está exenta de conflictos. Además, la comunidad se cohesiona en función de imaginarios globales de miedo, riesgo y amenaza, pero donde la cercanía de la pobreza los personaliza (CIPER, 2010). Estos signos muestran un tránsito de un fenómeno de segregación socioespacial a un fenómeno de polarización social en estructuras urbanas fragmentadas.
El capital inmobiliario a través de la inversión en proyectos habitacionales para estratos medios y altos en sectores homogéneos en pobreza, ha generado una cercanía geográfica entre habitantes pobres y mejor situados, pero la vida urbana que se genera entre nuevos y antiguos vecinos está determinada por una dialéctica del miedo y la inseguridad. Los habitantes originarios de barrios adyacentes viven muy conscientes esta polarización en los estilos de vida y exclusión como un proceso doloroso y humillante, aunque con ciertas ventajas.

En Latinoamérica, la expansión de un sistema informal de cierres en calles se ha generalizado a la mayoría de las grandes ciudades (Plöger, 2006). Desde los años ochenta se habla en Latinoamérica de una era de inseguridad (age of insecurity) (Davis, 2006). El creciente sentimiento de inseguridad de la población aparece como de sentido común junto al factor de criminalidad (Wehrhahn \& Haubrich 2010). El potencial de inseguridad impacta directamente tanto a aquellos afectados por la criminalidad así como a las potenciales víctimas (Wehrhahn \& Haubrich, 2010; Galleguillos, 2012). La acción de cerrar lo que se considera descubierto o expuesto no encuentra correlato en los índices de riesgo objetivo, ni en los barrios en cuestión ni en las urbes chilenas en general (Galleguillos, 2013). En el contexto chileno, en comparación con otros países de la región, Chile tiene una tasa baja de violencia, menor que la tasa mundial, medido por la tasa de homicidios. Llama la atención además, que análogamente, el área metropolitana de Santiago concentra la mayor proporción de inseguridad y poder diferenciado socioespacialmente (Paulsen, 2008, Briceño-León, 2008, CIPER, 2010).

No existe una correlación directa entre el desarrollo de la criminalidad y el sentimiento de inseguridad percibido en la sociedad. El sentido de inseguridad es un fenómeno generalizado y parece ser de importancia mayor que la amenaza real (Wehrhahn y Haubrich, 2010). Los delitos se repiten en los mismos sitios año tras año y las zonas más peligrosas de Santiago siguen siendo perfectamente identificables. Las causas, entre otras, señalan un actuar delictual exacerbado y anclado en diferencias raciales, socioeconómicas de clase y de género, por la televisión y medios 
de comunicación de masas (CIPER, 2010; Galleguillos, 2012). De absoluto consenso es que no existen diferencias fenotípicas entre los seres humanos, relevantes para el ensayo del comportamiento social, de tal manera que este ideario de pertenencia racial no es más que una construcción social (Smith, 1989; Molina, 2001). No obstante, en la práctica la creencia en la legitimidad de tales diferencias biológicas ha situado a una gran parte de la humanidad en una condición social, política, económica y cultural de opresión y subordinación (Molina, 2001). Una revisión de autores clásicos críticos a la zonificación social y funcional y comprometidos con la calidad de vida en las ciudades, muestra aportes como el de Jacobs (1993) que plantea que los espacios comunitarios deben tener una escala humana pues constituyen el entorno de aprendizaje y socialización, se trata de facilitar la generación de vecindad y promover la emergencia de sentimientos de comunidad. En esta línea de argumentación, Sennet (1975) defiende la diversidad social como fuentes de energía y transformación cultural. El papel del espacio urbano es conectar y mezclar las personas, rompiendo su rutina tradicional y su anquilosamiento social (Sennet, 1975).

Por su parte Rapoport (1978) defiende la diversidad sociocultural a partir de clusters homogéneos, como fuente de energía y de transformación cultural. El medio ambiente es ante todo un instrumento de recuperación, separación y protección según este autor, por lo que un cierto "orden" generado por los propios habitantes es esencial. Entonces la integración de lo diverso se da en base a reconocer las diferencias y el agrupamiento de los iguales. Esto se logra a través del diseño de zonas próximas para que cada grupo pueda aprender de los otros (Rapoport, 1978). Una situación óptima sería aquella en que hay diferenciación social sin exclusión insistiendo en que los bordes de las áreas que ocupa cada grupo tienen que ser difusos (Young, 1995). En la medida que la ciudad obliga a la convivencia y a definir políticas de integración de las "diferencias" que a menudo están en el origen de la inseguridad y del miedo, es el único espacio capaz de mitigar verdaderamente el miedo sin renunciar a esta complejidad. Es decir, desde esta perspectiva la ciudad sería un antídoto contra el miedo, pero no tan solo por la tradición histórica de lugar cerrado y de comunidad humana sino, por la ciudad como espacio de convivencia y de intermediación entre intereses diversos y contrapuestos. Para muchos autores se trata de una característica definitoria de la ciudad. Sin ella la ciudad no existe (Indovina, 1990).

Habitar es también desarrollar las redes diferenciales en las que vivimos. Estructurar las necesidades por sus propias redes de convivencia. No es segregar ni polarizar sino tejer otras redes más amplias sobre las ya existentes, respetando las formas diferenciales de origen. No apoyando las desigualdades sino las diferencias, promoviendo la igualdad de oportunidades a favor de los estratos más pobres, pero no el igualitarismo con las mismas formas urbanas. Que cada cual pueda homologarse con otras áreas de convivencia vecinas en servicios o calidades de habitar es contribuir a configurar desde cada caso concreto soluciones no segregativas (Villasante, 1998). La convivencia de las clases sociales es una necesidad y un beneficio tanto para las clases acomodadas, como para las modestas. Nuestras ciudades generan cesantes que se transforman en marginales. Los empleos de proximidad, de servicios de persona a persona, o el mantenimiento urbano, el cuidado de espacios y equipamientos colectivos en las unidades residenciales, ofrecen posibilidades infinitas. La convivencia, el conocernos unos y otros, el hablarnos en las calles y plazas, es el mejor remedio a los sentimientos de inseguridad. La apuesta va por el camino de recuperar una mayor capacidad de razonar a partir de la sensibilidad. Una ciudad que nos acoja y nos proteja, una ciudad que nos permita ejercer el derecho a la ternura (Restrepo, 1994).

Actualmente, en el contexto latinoamericano como global, se discute fuertemente sobre medidas de mejoramiento de la calidad de vida en las ciudades. Entre ella, cobra significancia la promoción de diversidad socioespacial como la vida comunitaria entre distintas generaciones, diferentes grupos étnicos, entre ricos y pobres, y también como herramienta estratégica de planificación para rescatar la ciudad íntegra de su proceso de segmentación con nuevas conexiones y redes que apoyen la cohesión comunitaria en la reducción de conflictos y las causas de estos, 
y con esto contrarrestar procesos de autoconfinamiento y polarización (vivir detrás de muros y rejas) y en general promover un uso sustentable del espacio urbano. Aunque la vida en la ciudad así como la experimentamos ahora, muestra muchas fronteras y exclusiones, nuestra actual experiencia de la vida urbana también nos entrega avisos de lo que diferenciación sin exclusión podría ser. Aunque muchos barrios tienen diferentes identidades étnicas, igualmente cohabitan en ellos integrantes de otros grupos sociales. En la "buena" ciudad, uno traspasa de un entorno habitacional al otro sin saber exactamente dónde termina el primero y empieza el otro. En la normativa ideal de la vida urbana las fronteras son abiertas y no claramente delimitables.

La persistencia de procesos de desarticulación a que la mayoría de los habitantes chilenos de barrios periféricos en las grandes ciudades están expuestos, el bloqueo de la relación entre los vecinos, la discriminación entre ricos y pobres en la dotación de infraestructura urbana e iniciativas privadas, y la dureza de las condiciones de vida en la ciudad, que en los últimos años se han agravado por un aumento de la violencia y criminalidad, nos plantean la cuestión ineludible del rol social del desarrollo urbano. La implementación de contramedidas para enfrentar este desarrollo y estrategias activas contra la diferenciación socioespacial son desafíos muy complejos y que van más allá de lo que se puede observar y abarcar bajo los términos de planificación para el desarrollo urbano. No basta un desempeño eufemístico con la utopía de la heterogeneidad socioespacial para reducir conflictos urbanos, mejorar la calidad de vida de los habitantes y lograr mayor sustentabilidad para la vida en las ciudades. Es tarea de una planificación crítica darse cuenta de la necesidad de reconocer el espacio para grandes diferencias entre los vecinos en una intensa vida urbana. Estas diferencias deben ser posibles y para ello, los espacios públicos, avenidas y calles de las grandes ciudades deben ser dotados de un equipamiento que permita a las personas "de afuera" convivir en paz en forma respetuosa y dignificada. Las diferencias entre grupos debieran poderse manifestar libremente a través de la formación o constitución de grupos de afinidad. La diferenciación social y espacial no debiera ser excluyente, sino materia de conciencia social y colaboración mutua. La vida urbana manifiesta las contradicciones sociales y diferencias como un reto hacia el logro de una convivencia diferenciada por su historia y su sentido sociológico de comunidad.

La nueva Política Nacional de Desarrollo Urbano ha sido recientemente aprobada, luego de casi 30 años desde su última versión y de estar derogada desde el año 2000. Un documento que no tiene fuerza de ley ni carácter vinculante, aunque se trata de un documento que podría ser de gran relevancia para el futuro del país. La Política Nacional de Desarrollo Urbano podría orientar la institucionalidad, legislación y programas para tener mejores ciudades y calidad de vida. Un aspecto clave es el de comprometer al Estado en revertir las dinámicas de segregación, exclusión e inequidad urbana que se dieron en este tiempo, de manera de buscar una mejor integración social, garantizando el acceso universal a las oportunidades que ofrecen nuestras ciudades. Entre las prioridades para su implementación, está legislar para que instrumentos tan importantes como los planos reguladores, ordenanzas, pagos por impactos, contribuciones y otros mecanismos de planificación se adecuen y sean coherentes con la política, orientando en forma proactiva y participativa el desarrollo y conservación de nuestras ciudades. Además, velar por la conservación del patrimonio arquitectónico y urbano, desde el reconocimiento del barrio y las identidades locales. Por último, avanzar hacia una planificación que facilite conductas y estilos de vida más sustentables.

Las reflexiones se orientan en el camino de promover el enfoque del urbanismo ciudadano caracterizado por una política urbana, centrada en la valoración de la realidad plural y diversa de los barrios y comunidades. Los ideales de satisfacción residencial y los imaginarios de la promesa inmobiliaria (Lindon, 2006), como se muestran en este ejercicio, dan como resultado la emergencia de barrios latino gentrificados y barrios polarizados enrejados. El concepto de gentrificación tal como fue definido en sus orígenes, por los patrones de uso de suelo y oferta del mercado de suelo, así como en las tendencias sociales y nuevos tipos de 'gentrificadores' y sus estilos de vida urbana encontrados par- 
ticularmente en los barrios históricos de las ciudades europeas y norteamericanas, al aplicarlo, muestra importantes distinciones desde lo que se conocía como proceso esporádico en su origen (1960s), a lo que se observa en la actualidad como un fenómeno global.

\section{Referencias bibliográficas}

ALMANDOZ, A. Urban Planning and Historiography in Latin America. Progress in Planning, 2006, № 65, Vol. 2, p. 81-123.

APPLEYARD, D. The Conservation of European Cities. Cambridge \& London: MIR Press, 1979.

ARIZAGA, D. Recuperación de las áreas centrales. En: JORDÁN, R. y SIMIONI, S. (editores). Gestión Urbana para el Desarrollo Sostenible en América Latina y el Caribe. Santiago de Chile: CEPAL y Cooperazione Italiana, 2003, p. 203-245.

ARRIAGADA, C.; MORENO, J. y CARTIER, E. Evaluación de Impacto del Subsidio de Renovación Urbana en el Área Metropolitana del Gran Santiago 1991-2006. Política Habitacional y Planificación. Santiago de Chile: DITEC, MINVU, 2007.

ASCHER, F. Metapolis ou l'avenir des viIles. París: Odile Jacob, 1995.

BÄHR, J. y RIESCO, R. Estructura urbana de las metrópolis latinoamericanas: El caso de la ciudad de Santiago. Revista de Geografía Norte Grande, 1981, № 8, p. 27-55.

BALCHIN, J.P.; KIEVE, J. \& BULL, G. Urban Land Economics and Public policy. London: Macmillan Education Ltda, 1988.

BAUMAN, Z. Daños Colaterales. Desigualdades Sociales en la Era Global. México: Fondo de Cultura Económica, 2011.

BAUMAN, Z. Comunidad. En busca de seguridad en un mundo hostil. Madrid: Editorial Siglo XXI de España, 2006.

BECERRIL-PADUA, M. Policentrismo en las Ciudades Latinoamericanas. El Caso de Santiago de Chile. Revista Theomai, 2000, № 1, s/p.
BECK, U. La sociedad del riesgo global. Madrid: Siglo XXI, 2002.

BONDI, L. Gender, Class and Gentrification: Enriching the Debate. Environment and Planning D: Society and Space, 1999, Vol. 3, $N^{\circ} 17$, p. 261-282.

BORJA, J. y CASTELLS, M. Local y global: la gestión de las ciudades en la era de la información. Madrid: Taurus, 1997.

BORJA, J. La ciudad conquistada. Ciudad, espacio público y ciudadanía. Madrid: Alianza Editorial, 2003.

BORSDORF, A.; HIDALGO, R. \& SÁNCHEZ, R. A New Model of Urban Development in Latin America: The Gated Communities and Fenced Cities in the Metropolitan Areas of Santiago de Chile and Valparaíso. Cities, 2007, № 24, Vol. 5, p. 335-398.

BOURDIEU, P. Das Elend der Welt. Zeugnisse und Diagnosen alltäglichen Leidens an der Gesellschaft. Konstanz: Universitäts-Verlag Konstanz, 1997.

BRICEÑO-LEÓN, R. La violencia homicida en América Latina. América Latina Hoy, 2008, No 50, p. 103-116.

BUTLER, T. \& HAMNETT, C. Gentrification, Class and Gender: Some Comments on Warde's Gentrification as Consumption. Environment and Planning D: Society and Space, $1994, N^{\circ} 12$, p. 477-493.

CALDEIRA, T. City of Walls: Crime, Segregation, and Citizenship in São Paulo. London \& Berkeley: University of California Press, 2000.

CAMERON, S. \& COAFFEE, J. Art, Gentrification and Regeneration - From Artist as Pioneer to Public Arts. European Journal of Housing Studies, 2005, № 5, Vol. 1, p. 39-58.

CARPENTER, J. \& LEES, L. Gentrification in New York, London and Paris: An International Comparison. International Journal of Urban and Regional Research, 1995, Vol. 2, $\mathrm{N}^{\circ} 19$, p. 286-303.

CHERMAYEFF, S. \& ALEXANDER, C. Comunidad y privacidad: hacia una nueva 
arquitectura humanista. Buenos Aires: Nueva Visión, 1973.

CICCOLELLA, P. Globalización y dualización en la Región Metropolitana de Buenos Aires: Grandes Inversiones y Reestructuración Socioterritorial en los Años Noventa. EURE, 1999, Vol. 76, № 25, p. 5-27.

CIPER. Dónde y cómo se roba en Santiago: Mapa del fracaso policial. Gustavo Villarrubia, Reportajes de investigación. 2002. Disponible en internet: http://ciperchile. cl/2010/08/02/donde-y-como-se-roba-ensantiago-mapa-del-fracaso-policial/

CONTRERAS, Y. La recuperación urbana y residencial del centro de Santiago: Nuevos habitantes, cambios socioespaciales significativos. EURE, 2011, Vol. 112, No 37, p. 89-113.

CRENSHAW, K. Cartographies des marges: Interseccionalité, politique de l'identité et violences contre les femmes de couleur. Les Cahiers du Genre, 2005, №39, p. 51-82.

DAHER, A. Neoliberalismo Urbano en Chile. Ensayos Públicos, 1991, № 43, p. 281-299.

DAMMERT, L.; KARMY, R. y MANZANO, L. Ciudadanía, Espacio Público y Temor en Chile. Santiago de Chile: Centro de Ensayos en Seguridad Ciudadana, Universidad de Chile, 2003. Disponible en internet: http://www. cesc.uchile.cl/publicaciones/se_10_ciudadania.pdf.

DAVIDSON, M. \& LEES, L. New-Build Gentrification: Its Histories, Trajectories, and Critical Geographies, Population. Space and Place, 2010, No 16, p. 395-411.

DAVIS, D. The Age of Insecurity: Violence and Social Disorder in the New Latin America. Latin American Research Review, 2006, Vol. 1, No 41, p. 179-197.

DE MATTOS, C. Transformación de las Ciudades Latinoamericanas: ¿Impactos de la Globalización?' EURE, 2002, Vol. 85, № 28, p. 5-10.

DE MATTOS, C. Santiago de Chile, Globalización y Expansión Metropolitana: Lo
Que Existía Sigue Existiendo. EURE, 1999, Vol. 76, N²5, p. 29-56.

DE MATTOS C.; RIFFO, L.; YÁÑEZ, G. y SALAS, X. Reestructuración del Mercado Metropolitano de Trabajo y Cambios Socio Territoriales en el Gran Santiago. Reporte final. Santiago de Chile: IEUT, 2005. Disponible en internet: http://www.geo.puc.cl/observatorio/ arenas/Mercado\%20de\%20Trabajo\%202004. pdf

DINGES, M. \& SACK, F. Unsichere Großstädte? Vom Mittelalter bis zur Postmodernen. Konstanz: U Universitäts-Verlag Konstanz, 2000.

DORLIN, E. Performe ton genre: Performe ta race!. Repenser I'articulation entre sexisme et racisme à l'ère de la postcolonie. In: VERSCHUUR, Ch. Genre, postcolonialisme et diversité des mouvements de femmes. Geneva: L’Harmattan, 2007, p. 227-237.

DUCCl, M. E. Área Urbana de Santiago 1991-2000: Expansión de la Industria y la Vivienda. EURE, 2002, Vol. 85, No 28, p. 187-207.

EL MERCURIO. Cruda realidad en las poblaciones donde impera la ley de los traficantes: 200 mil vecinos viven como rehenes de los narcos en los barrios peligrosos del país. Santiago de Chile: El Mercurio, 2009a.

EL MERCURIO Las comunas más pobladas de Santiago tienen más de 800 calles y pasajes enrejados. Santiago de Chile: El Mercurio, 2009b.

ELLIN, N. Post-modern urbanism. Cambridge: Blackwell, 1996.

ELLIN, N. Architecture of fear. Nueva York: Princeton Architectural Press, 1997.

FITCH, J. Historic Preservation: Curatorial Management of the Built World. CharlottesviIle: University Press of Virginia, 1990.

FUENTES, L. y SIERRALTA, C. Santiago de Chile. ¿Ejemplo de una Reestructuración Capitalista Global? EURE, 2004, Vol. 91, Nº 30, p. 7-28. 
GALLEGUILLOS, X. Vertane Chancen: Der Wiederaufbau nach der Erdbeben- und Tsunami-Katastrophe in Chile vom Februar 2010. Geographische Rundschau, 2013, Nº 12 , p. $48-51$.

GALLEGUILLOS, X. Social Environmental Conflicts and Urban Lifestyles - New Patterns of Spatial Segregation in Santiago de Chile. In: SANDNER LE GALL, V. \& WEHRHAHN, R. (editors). Geographies of Inequality in Latin America. Kiel: Selbstverlag des Geographischen Instituts der Universität Kiel, 2012, p. 357-376.

GALLEGUILLOS, X. Möglichkeiten zum Abbau von Segregation in Armenvierteln: Die Frage nach der sozialen und ökonomischen Nachhaltigkeit urbaner Ballungsräume am Beispiel Santiago de Chile Kiel: Kieler Geographische Schriften Band 115, 2007.

GARNER, S. Racialisation en Racisms: An Introduction. London: SAGE Publications, 2010.

GARREAU, J. Edge city: life in the new frontier. Nueva York: Doubleday, 1991.

GLASS, R. London: Aspects of Change. London: Centre for Urban Studies and MacGillion \& Kee, 1964.

GRAHAM, R. The Idea of Race in Latin America 1870-1940. Texas: University of Texas Press, 1990.

GUROVICH, A. Conflictos y Negociaciones. La Planificación Urbana en el Desarrollo del Gran Santiago. Revista de Urbanismo, 2000, No 2. Disponible en Internet: http:// www.revistas.uchile.cl/index.php/RU

HACKWORTH, J. \& SMITH, N. The Changing State of Gentrification. Tijdschrift voor Eonomische en Sociale Geoprafie, 2001, Vol. 4, No 92, p. 464-477.

HAMNETT, C. Unequal City. London in the Global Area. London: Routledge, 2003.

HAMNETT, C. The Blind Men and The Elephant; The Explanation of Gentrification. Transactions of Institute of British Geographers, 1991, N 16, p. 173-189.
HARDOY, J. \& M. GUTMAN Impacto de la Urbanización en los Centros Históricos de Iberoamérica. Tendencias y Perspectivas. Madrid: MAPFRE, 1992.

HARRIS, C. D. \& ULLMAN, E. L. The Nature of Cities. Annals of the American Academy of Political and Social Science, 1945, № 242, p. 7-17.

HARVEY, D. El nuevo imperialismo: acumulación por desposesión. En: PANTICH, L. y COLIN, L. (editores). El Nuevo desafío Imperial, Buenos Aires: Merlin Press-Clacso, 2004, p. 99-129.

HAYDEN, D. The Power of Place: Urban Landscapes as Public History. Cambridge, MA: MIT Press, 1995.

HEBBERT, M. The Street as Locus of Collective Memory. Environment and Planning D: Society and Space, 2005, № 23, p. 581596.

HIDALGO, R., SALAZAR, A. y ÁLVAREZ, L. Los Condominios y Urbanizaciones Cerradas como Nuevo Modelo de Construcción del Espacio Residencial en Santiago de Chile (1992-2000). Scripta Nova. Revista electrónica de Ciencias Sociales, 2003, Vol. 123, $\mathrm{N}^{\circ}$ 146. Disponible en internet: http://www. ub.edu/geocrit/sn/sn-146(123).htm

HOYT, H. The Structure and Growth of Residential Neighborhoods in American Cities. Washington, D.C.: Federal Housing Administration, 1939.

INDOVINA, F. La città diffusa. Venecia: DAEST, 1990.

INSTITUTO NACIONAL DE ESTADÍSTICA (INE). Censo de Población y Vivienda. Santiago de Chile: INE, 1992.

INSTITUTO NACIONAL DE ESTADÍSTICA (INE). Censo de Población y Vivienda. Santiago de Chile: INE, 2002.

INZULZA, J. Latino-gentrification? Focusing on physical and socioeconomic patterns of change in Latin American inner cities. Urban Studies, 2012a, Vol. 10, № 49, p. 20852107. 
INZULZA, J. Changes to Contemporary urban culture in Latin America: experiences of everyday life from the core of Santiago, Chile. In: EDENSOR, T. \& JAYNE, M. (editors). Urban Theory beyond 'The West'. A World of Cities. London \& New York: Routledge, 2012b, p. 207-216.

INZULZA, J. Continuity and change in an historic neighbourhood of Santiago, Chile: the gentrification of Bellavista 1990 - 2009. Tesis doctoral. Manchester, UK: The University of Manchester, 2009.

JACOBS, J. The Death and Life of Great American Cities. New York: Random House, 1961.

JANOSCHKA, M. El nuevo modelo de la ciudad latinoamericana: fragmentación y privatización. EURE, 2002, № 28, Vol. 85. Disponible en Internet: http://www. scielo.cl/scielo.php?script=sci_arttext\&pid =S0250-71612002008500002.

LADD, B. Urban Planning and Civic Order in Germany, 1860-1914. Harvard: Harvard University Press, 1990.

LEES, L. In the Pursuit of Difference: Representations of Gentrification. Environment and Planning $A, 1996, N^{\circ} 28$, p. 453-470.

LEES, L. Rethinking Gentrification: Beyond the Positions of Economics or Culture. Progress in Human Geography, 1994, Vol. 2, Nº 18 , p. $137-150$.

LEES, L.; SLATER, T. \& WYLY, E. Gentrification. New York \& London: Routledge, 2008.

LEES, L. \& LEY, D. Introduction to Special Issues on Gentrification and Public Policy. Urban Studies, 2008, Vol. 12, № 45, p. 2379-2384.

LEY, D. The Rent Gap Revisited. Annals of the Association of American Geographers, 1987, Vol. 3, No 77 , p. 465-468.

LINDÓN A.; AGUILAR, M. y HIERNAUX, D. Lugares e imaginarios en la metrópolis. Barcelona: Editorial Antrophos, 2006.

LÜDEMANN, C. Kriminalitätsfurcht im urbanen Raum. Eine Mehrebenenanalyse zu individuellen und sozialräumlichen Determinanten verschiedener Dimensionen von Kriminalitätsfurcht. Kölner Zeitschrift für Soziologie und Sozialpsychologie, 2006, Vol. 2, No58, p. 285-306.

LUNGO, M. \& BAIRES, S. Socio-Spatial Segregation and Urban Land Regulation in Latin American Cities. Washington D.C.: Lincoln Institute of Land Policy, 2001.

LYNCH, K. Site Planning. Cambridge: M.I.T. Press, 1971.

LYONS, M. Gentrification, Socio-Economic Change and the Geography of Displacement. Journal of Urban Affairs, 1996, № 18, p. 39-62.

MARTÍNEZ, V. El enfoque Comunitario. Santiago de Chile: FACSO y Universidad de Chile, 2006.

MINISTERIO DE PLANIFICACIÓN (MIDEPLAN). Encuesta de Caracterización Socioeconómica Nacional CASEN. Santiago de Chile: MIDEPLAN, 2000.

MOLINA, I. Segregación habitacional étnica en la ciudad sueca. Un proceso de racialización. Scripta Nova. Revista electrónica de Geografía y Ciencias Sociales, 2001, Nº 90. Disponible en Internet: http://www.ub.edu/ geocrit/sn-90.htm

MOLINA I. El Programa de Erradicación de Campamentos en la Región Metropolitana: Implicancias Socioeconómicas y Espaciales. Memoria de Geografía. Santiago de Chile: Instituto de Geografía, Pontificia Universidad Católica de Chile, 1985.

MOLINA, I. y GALLEGUILLOS, X. Esperanza Andina. Segregación y posibilidades de rescate de una heterogeneidad urbana. El rol de las mujeres. En: MOLINA, I. (editor). Rompiendo barreras. Género y espacio en el campo y en la ciudad. Santiago de Chile: Corporación libertades ciudadanas/University of Uppsala, 2006, p. 187-201.

MORALES, E. y ROJAS, S. Relocalización Socioespacial de la Pobreza. Política Estatal y Presión Popular 1979-1985. Santiago de 
Chile: Facultad Latinoamericana de Ciencias Sociales-FLACSO, 1986.

NAREDO. J. Sobre el origen, el uso y el contenido del término sostenible. En: Primer catálogo español de Buenas Prácticas. Madrid: Centro de Publicaciones, Secretaría General Técnica del Ministerio de Obras Públicas y Urbanismo, 1996, Vol. 1, s/p.

NEWMAN, O. Defensible Space. New York: Macmillian, 1972.

ORMINDO, P. Formación en Conservación de Monumentos y Gestión Integral del Patrimonio en América Latina y el Caribe. Santiago de Chile: UNESCO-OEI, 2002.

PARK, R.; BURGESS, E. \& MCKENZIE, R. The City. Chicago: University of Chicago Press, 1925.

PAULSEN, G. El temor a la delincuencia en Chile. Bogotá: Cámara de Comercio de Bogotá, 2008. Disponible en Internet: http:// camara.ccb.org.co/documentos/ 3774_foro_ percepcion_parte_1.pdf vista 07.05.2012.

PAVEZ, M. I. Los conceptos de unidad vecinal y de barrio en la teoría y práctica urbanística. Antigüedad, siglo XIX y siglo XX. Documento de Apoyo Docente FAU, Serie DOC, No 474, 2008, s/p.

PLÖGER, J. Practices of Socio-spatial Control in the Marginal Neighbourhoods of Lima, Peru. Trialog, 2006, № 90, p. 32-36.

RAPOPORT, A. Aspectos humanos de la forma urbana. Hacia una confrontación de las ciencias sociales con el diseño de la forma urbana. Barcelona: Gustavo Gili, 1978.

RESTREPO, L. El derecho a la ternura. Bogotá: Arango Editores, 1994.

ROBERTSON, R. Glocalización: tiempoespacio y homogeneidad-heterogeneidad. Cansancio del Leviatán: problemas políticos de la mundialización. Madrid: Trotta, 2003.

ROCHA, R.; ANTILEF, P. y VILLAROEL, J. Santiago de Chile. Metropolización, Globalización, Desigualdad. EURE, 2001, № 27, Vol. 80, p. 121-139.
ROJAS, E. Volver al Centro. La Recuperación de las Urbanas Centrales. Washington, D.C.: Banco Interamericano de Desarrollo, 2004.

RUBINO, S. A Curios Blend? City Revitalisation. Gentrification and Commodification in Brazil. In: ATKINSON, R. \& BRIDGE, G. Gentrification in a Global Context: The New Urban Colonialism. London: Routledge, 2005, p. 225-239.

SABATINI, F. y ARENAS, F. Entre el Estado y el Mercado: Resonancias Geográficas y Sustentabilidad Social en Santiago de Chile. EURE, 2000, Vol. 79, № 26, p. 95-113.

SASSEN, S. The Global City: New York, London, Tokyo. Princeton, New Jersey: Princeton University Press, 1991.

SELIGMAN, M. Erlernte Hilflosigkeit. München, Wien, Baltimore: Urban und Schwarzenberg, 1979.

SENNET, R. Vida urbana e identidad personal. Barcelona: Península, 1975.

SEREX. Evaluación del Potencial Inmobiliario de Terrenos EFE/INVIA en el Anillo Central Metropolitano. Santiago de Chile: Ensayos Territoriales, Pontificia Universidad Católica de Chile, 2002.

SHAFER, T. Urban Growth \& Economics. Reston: Reston Publishing Company, 1977.

SMITH, D. "Studentification": the Gentrification Factory? In: ATKINSON, R. \& BRIDGE, G. Gentrification In A Global Context: The New Urban Colonialism. London: Routledge, 2005, p. 72-89.

SMITH, N. The new urban frontier. Gentrification and the revanchist city. London: Routledge, 1996.

SMITH, S. The politics of 'Race' and Residence. Citizenship, Segregation and White Supremacy in Britain. Oxford: Polity Press, 1989.

SOJA, E. Postmetropolis. Critical studies of cities and regions. Oxford: Blackwell, 2000. 
THE WORLD BANK. World Development Report 2000/2001: Attacking Poverty. New York: Mundi Prensa Libros, 2000.

THOMPSON, F.M.L. Gentrification and The Enterprise Culture: Britain 1780-1980. Oxford: Oxford University Press, 2001.

ULUSOY, Z. Housing Rehabilitation and its Role in Neighborhood Change: a Framework for Evaluation. Journal of Architectural and Planning Research, 1998, № 15, p. 243-257.

VALENZUELA, M. Programa de Repoblamiento Comuna de Santiago: Un Programa de Gestión Urbana. Urbano, 2004, Vol. 9, № 7, p. 12-17.

VAN KAMP. I.; LEIDELMEIJER, K.; MARSMAN, G. \& DE HOLLANDER, A. Urban environmental quality and human wellbeing. Towards a conceptual framework and demarcation of concepts; a literature study', Landscape and Urban Planning, 2003, № 65, p. 5-18.

VICENTE, J. ¿Nuevas ciudades, nuevas palabras? Revista de Geografía, 2003, №2, p. 79-103.

VILLASANTE, T. Cuatro redes para mejorvivir. Volumen 1: del desarrollo local a las redes para mejor vivir. Buenos Aires: Lumen/ Humanitas, 1998.

VIVEROS, M. La sexualización de la raza y la racialización de la sexualidad en el contexto latinoamericano actual. Revista Latinoamericana de Ensayos de la Familia, 2009, № 1, p. 63-81.
WACQUANT, L. El Diseño de la Seclusión Urbana en el Siglo XXI. Herramientas, 2011, $N^{\circ} 48$, p. 9-26.

WACQUANT, L. Las dos caras de un gueto. Ensayos sobre marginalización y penalización. Buenos Aires: Siglo XXI, 2010.

WEHRHAHN, R. \& HAUBRICH, D. Megastädte im globalen Süden. Dynamik und Komplexität megaurbaner Räume mit Beispielen aus Lima und Guangzhou. Geographische Rundschau, 2010, Vol. 10, Nº2, p. 30-37.

WEHRHAHN, R. \& LUKAS, M. Neoliberale Stadtpolitik in Santiago de Chile. Prozesse, Akteure und Konflikten. Geographische Rundschau, 2013, N 12, p. 30-37.

WILSON, J. \& KELLING, G. Broken windows. The police and neighborhood safety. Atlantic Monthly, 1982, Vol. 3, N²49, p. 29-38.

WYLY, E. \& HAMMEL, D. Mapping NeoLiberal American Urbanism. In: ATKINSON, R. \& BRIDGE, G. Gentrification in a Global Context: the New Urban Colonialism. London: Routledge, 2005, p. 18-38.

YOUNG, I. City Life and Difference. In: KASINITZ, P. Metrópolis. Center and Symbol of our Times. New York: New York University Press, 1995, p. 250-270.

ZUKIN, S. Loft Living: Culture and Capital in Urban Change. London: Radius, 1988. 
